\title{
Neuartige Wirkstoffabgabesysteme für die Glaukomtherapie: Hürden und Lösungsansätze für die Formulierung
}

\author{
Ognjenka Rahića Amina Tucak ${ }^{a}$ Naida Omerović ${ }^{b}$ Merima Sirbubalo ${ }^{a}$ Lamija Hindija $^{a}$ \\ Jasmina Hadžiabdića Edina Vranića
}

${ }^{a}$ Abteilung für pharmazeutische Technologie, Pharmazeutische Fakultät, Universität Sarajevo, Sarajevo, Bosnien und Herzegowina;

${ }^{b}$ Abteilung für klinische Pharmazie, Pharmazeutische Fakultät, Universität Sarajevo, Sarajevo, Bosnien und Herzegowina

\author{
Schlüsselwörter \\ Glaukom · neuartige okuläre Wirkstoffabgabesysteme · \\ Formulierung
}

\begin{abstract}
Zusammenfassung
Das Glaukom gilt als eins der größten gesundheitlichen Probleme weltweit. Es ist die häufigste vermeidbare Erblindungsursache zum Einen, weil es in der Frühphase asymptomatisch bleibt, zum Anderen wegen mangelnder Therapietreue der Patienten. Es gibt bei der Behandlung des Glaukoms verschiedene Herangehensweisen, die jeweils auf den Einzelfall abgestimmt werden müssen. Die erste Therapielinie ist eine medikamentöse Behandlung. Da jedoch die herkömmlichen Darreichungsformen zahlreiche Nachteile aufweisen, wird intensiv an der Entwicklung neuartiger Wirkstoffab-
\end{abstract}

gabesysteme für die Glaukomtherapie gearbeitet. Die vorliegende Übersichtsarbeit gibt einen Überblick über Lösungsansätze und Strategien bei der Entwicklung von Darreichungsformen wie in situ gelierenden Systemen, Nanosystemen, okulären Inserten, Kontaktlinsen, Cornea Shields aus Kollagen, okulären Implantaten, Mikronadeln und lontophoresesystemen. Ergänzend werden Ergebnisse von Studien zur Wirksamkeit dieser Wirkstoffabgabesysteme kurz vorgestellt.

(c) 2020 Die Autoren

\section{Neuartige Wirkstoffabgabesysteme}

Ein großes Problem in der Behandlung des Glaukoms ist, genau wie bei anderen chronischen Krankheiten, die mangelnde Therapietreue der Patienten. Zwar lässt sich vermeiden, dass das Glaukom zur Erblindung führt, wenn es in einem frühen Stadium diagnostiziert und korrekt behandelt wird, doch zahlreiche Studien belegen die Problematik einer intermittierenden Anwendung der Therapie [55-60]. Tsai et al. [55] identifizierten in ihrer Studie 71 Gründe für Nicht-Adhärenz, die sie in vier Kategorien einordneten: situations-/umgebungsbedingte Faktoren, Medikationsschema, patientenseitige Faktoren und behandlerseitige Faktoren. In einer von Newman-Casey et al. [60] durchgeführten Umfrage er- wies sich Vergesslichkeit der Patienten als der häufigste Grund für mangelhafte Adhärenz, gefolgt von unwirksamer Selbstanwendung (Verfehlen des Auges bei der Applikation der Tropfen) sowie Einstellungen der Patienten zum Glaukom (Patienten glaubten nicht, dass sie daran erblinden würden) und zur Medikation (Patienten glaubten, dass die Arzneimittel nicht wirken). Ein weiteres Problem sind die Nachteile der herkömmlichen Darreichungsformen ophthalmologischer Arzneimittel. Augentropfen sind zwar einfach herzustellen und machen über $90 \%$ aller Ophthalmika auf dem Markt aus, ihr großer Nachteil ist jedoch die geringe Bioverfügbarkeit (BV) des Wirkstoffs (unter 10\%) [61-64]. Einer der Gründe für die schlechte Wirkstoff-BV ist das begrenzte Fassungsvermögen des Bindehautsacks (typischerwei- 
se 7-10 $\mu \mathrm{L}$; maximal $50 \mu \mathrm{l})[61,65]$, ein weiterer ist der rasche $\mathrm{Ab}$ fluss des Arzneimittels infolge der Schwerkraft oder durch den Tränenkanal [62].

Seit einiger Zeit wird intensiv daran gearbeitet, neue Wirkstoffabgabesysteme zu entwickeln, die die Adhärenz der Patienten verbessern und die Beschränkungen der konventionellen Glaukomtherapie überwinden helfen. Bei der Entwicklung neuartiger Wirkstoffabgabesysteme für Ophthalmika (NODDS; Novel Ophthalmic Drug Delivery Systems) werden parallel zwei Ziele verfolgt [66]:

1 die Kontaktzeit des Wirkstoffs mit der Augenoberfläche zu verlängern und

2 die Elimination des Wirkstoffs zu verlangsamen.

Systeme mit verzögerter Wirkstofffreisetzung - sei es in Form von Gel-Tropfen oder von Implantaten, Inserten o. Ä. - stellen einen vielversprechenden Ansatz dar.

\section{In situ gelierende Systeme}

Einer der erfolgreichsten Ansätze zur Lösung der Probleme mit den konventionell formulierten Ophthalmika ist die Erhöhung der Viskosität mithilfe verschiedener gelbildender Polymere [6668]. Da es bei Formulierungen mit zu hoher Viskosität zu einem Fremdkörpergefühl im Auge und zu verschwommenem Sehen kommen kann, ist es sehr wichtig, die optimale Viskosität und das optimale rheologische Profil dieser Formulierungen zu ermitteln [69].

Studien haben ergeben, dass das gewünschte Fließverhalten für Augengel-Formulierungen das einer pseudoplastischen Flüssigkeit ist, um beim Blinzeln nicht zu stören. Diese Formulierungen sind durch hohe Viskosität bei niedrigen Schergeschwindigkeiten und niedrige Viskosität bei hohen Schergeschwindigkeiten gekennzeichnet [70-72].

Die Entwicklung von in situ gelierenden Systemen (IGS), auch als Sol-Gel-Systeme bezeichnet, hat große Aufmerksamkeit erlangt, insbesondere im Hinblick auf die verzögerte Wirkstoffabgabe (Abbildung 1A). Sie zeigen ihr spezifisches Verhalten, weil sie Polymere enthalten, die als intelligent oder Stimuli-responsiv bezeichnet werden, da sie auf bestimmte Reize reagieren und infolge geringfügiger Veränderungen in ihrer Umgebung bemerkenswerte physikalisch-chemische Veränderungen durchlaufen [62, 73].

Aufgrund ihrer spezifischen physikalisch-chemischen Eigenschaften liegen IGS in Form viskoser Flüssigkeiten vor. Dadurch können sie wie konventionelle Augentropfen instilliert werden, was im Hinblick auf die einfache Verabreichung und Sicherheit von Vorteil ist. Sobald jedoch die Flüssigkeit die Augenoberfläche erreicht, bewirken die «intelligenten» Polymere infolge bestimmter Stimuli oder Reize die Umwandlung in ein Gel. Diese Reize können über ein elektrisches oder magnetisches Feld, Ultraschall- oder Lichtwellen oder durch eine Veränderung des $\mathrm{pH}$ Werts, der Temperatur oder der Ionen in der Umgebung sowie durch die Gegenwart bestimmter Enzyme oder Antigene ausgeübt werden [74-76].

\section{Thermosensitive IGS}

AufTemperaturänderungen reagierende IGS sind die älteste, aber nach wie vor die gebräuchlichste Art von IGS für die okuläre Wirkstoffapplikation. Es wird empfohlen, dass die Umwandlung in den Gelzustand oberhalb der Raumtemperatur erfolgt, vorzugsweise bei der präkornealen Temperatur. Tatsächlich liegt die Gelierungstemperatur bisher entwickelter IGS bei $35^{\circ} \mathrm{C}$, was der präkornealen Temperatur entspricht [77].

Im Folgenden werden Poloxamere ${ }^{\circledR}$, Xyloglucan und Poly(N-isopropylacrylamid) (PNIPAAm) als in Ophthalmika häufig verwendete thermosensitive Polymere vorgestellt [62, 64, 65]

\section{Poloxamere $^{\circledR}$}

Poloxamere ${ }^{\circledR}$ sind Polymere, die aus drei Blöcken von Copolymeren bestehen: Poly(ethylenoxid)-poly(propylenoxid)poly(ethylenoxid) (PEO-PPO-PEO). Sie zeichnen sich dadurch aus, dass sie funktionelle Gruppen aufweisen, die ihnen Amphiphilie verleihen - hydrophile Ethylenoxid-Gruppen und hydrophobe Propylenoxid-Gruppen. Bei Körpertemperatur und in einer Konzentration von mehr als 15\% gehen sie in einen Gelzustand über. Die Mechanismen, die diese Umwandlung in ein Gel bewirken, sind Polymer-Desolvatisierung, vermehrte Mizellenaggregation und vermehrte Verschlaufung der Polymernetzwerkstruktur [65, 78]. Diese Stoffe sind auch unter den Handelsnamen Pluronic ${ }^{\circledR}$ und Tetronic ${ }^{\circledR}$ erhältlich [78].

In Ophthalmika wird häufig Pluronic ${ }^{\circledR}$ F-127 (PF-127) oder Poloxamer $^{\circledR} 407$ (P407) verwendet. Nach der temperaturinduzierten Umwandlung ergibt dieses Polymer ein klares, farbloses und durchsichtiges Gel. Der Übergang zum Gel erfolgt in Formulierungen mit einem Gehalt von 20-30\% PF-127, was eine hohe Konzentration darstellt, die Reizungen des Auges hervorrufen kann [62, 78]. Hinzu kommt: Als Gupta und Samanta [79] untersuchten, ob sich eine IGS-Formulierung von Forskolin entwickeln lässt - einem aus der Pflanze Caleus forskohlii isolierten Diterpenoid, das bei Tieren und Menschen den AID senkt, indem es den Kammerwasserabfluss fördert [80] -, wiesen sie nach, dass P407 in einer Konzentration über $25 \%$ bei niedriger Temperatur ein recht festes Gel bildet, was das Einträufeln der Lösung ins Auge erschwert. Deshalb erstellten sie Formulierungen mit 18, 20, 22 und 25\% P407 sowie mit Natriumchlorid für Isotonizität und Benzalkoniumchlorid als Konservierungsmittel und zur Förderung der Hornhautpenetration von Forskolin. Dabei erwies sich als optimale Formulierung die mit 22\% P407; sie zeigte eine verzögerte Wirkstofffreisetzung über $4 \mathrm{~h}$ und wirksame Senkung des AID für $12 \mathrm{~h}$ bei Weiße-Neuseeländer-Kaninchen. Bei der Anwendung dieser Formulierung wurden keine Nebenwirkungen beobachtet, und der messbare Forskolin-Gehalt in der Tränenflüssigkeit hatte $4 \mathrm{~h}$ lang Bestand, verglichen mit $0,5 \mathrm{~h}$ bei herkömmlichen Augentropfen, was auf eine verlängerte Verweilzeit an der Hornhaut schließen lässt [79].

Um die genannten Nachteile zu überwinden und mit einer niedrigeren PF-127-Konzentration auszukommen, wird intensiv an der Entwicklung von Kombinations-IGS gearbeitet, die ein Gemisch aus Polymeren mit unterschiedlichen Übergangs-Auslö-
48

Kompass Ophthalmol 2021;7:47-69

DOI: $10.1159 / 000516684$ 


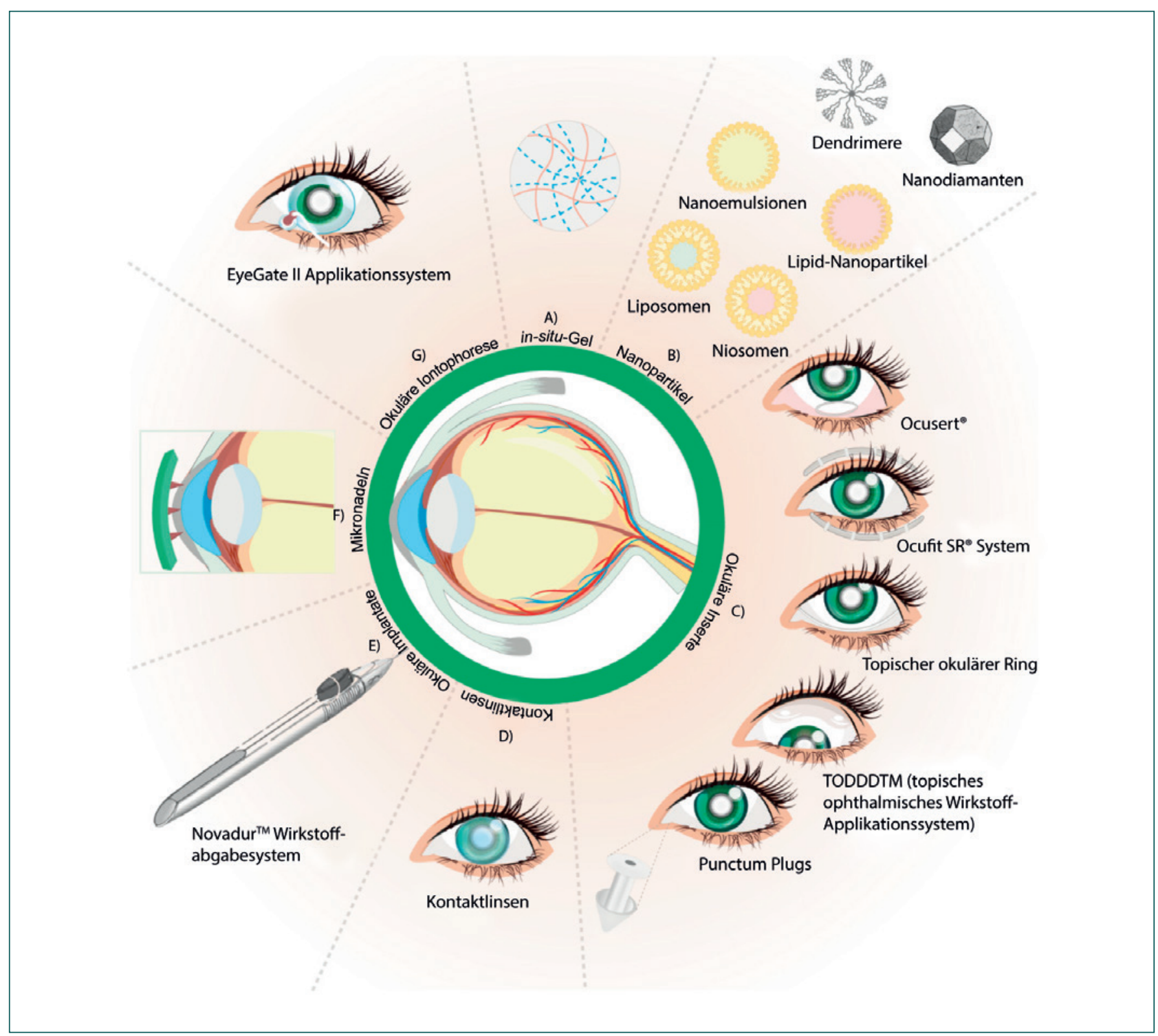

Abb. 1. Wirkstoffabgabesysteme für die Glaukombehandlung im Überblick. (A) In situ gelierende Systeme, (B) Nanopartikel: Liposomen, Niosomen, Nanopartikel, Lipid-Nanopartikel, Dendrimere, Nanodiamanten, (C) Okuläre Inserte: Ocusert ${ }^{\circledR}$, Ocufit SR ${ }^{\circledR}$ System, topischer okulärer Ring, TODDDTM (topisches ophthalmisches Arzneimittel-Applikationssystem), Punctum-Plugs, (D) Kontaktlinsen, (E) Okuläre Implantate: Novadur'T Wirkstoffabgabesystem, (F) Mikronadeln, (G) Okuläre lontophorese: EyeGate II Applikationssystem.

sern enthalten. Ein weiterer Ansatz, der verfolgt wird, ist die Kombination von PF-127 mit viskositätssteigernden Stoffen wie Hydroxypropylmethylcellulose (HPMC) oder Methylcellulose (MC) und zusätzlich mit isotonischen Substanzen wie Mannit oder Natriumchlorid [62, 78].

Betaxololhydrochlorid war in der Studie von Huang et al. das Mittel der Wahl. Am erfolgreichsten erwies sich in dieser Studie eine Formulierung mit 22\% P407 und 3,5\% P188 sowie Polycarbophil als Zusatz zur Erhöhung der Viskosität. Die Formulierung zeigte in in-vitro-Freisetzungsstudien eine flutartige Freisetzung von ca. $70 \%$ des Wirkstoffs in den ersten $3 \mathrm{~h}$; insgesamt erstreckte sich die Wirkstofffreisetzung auf 8 h. Die Formulierung erwies sich in vivo als nicht augenreizend; die pharmakokinetischen Tests in vivo ergaben eine höhere AUC in wässriger Lösung im Vergleich $\mathrm{zu}$ konventionellen Augentropfen, was auf eine möglicherweise verbesserte BV des Wirkstoffs hindeutet. Die AID-senkende Wirkung hielt für $12 \mathrm{~h}$ an [84]. Lad und Bajaj erstellten eine Formulierung aus Brinzolamid und 22\% P338 plus entweder HPMC K4M oder Carbopol 974 zur Viskositätssteigerung. Die Formulierung, mit der eine anhaltende Wirkstofffreisetzung für $24 \mathrm{~h}$ erreicht wurde, bestand aus 22\% P338 und 1\% HPMC K4M. Ex-vivo-Studien ergaben, dass in $24 \mathrm{~h} 85-88 \%$ des Wirkstoffs die 
Hornhaut passieren, während $10-13 \%$ des Wirkstoffs auf der Hornhautoberfläche verblieben, was auf eine verzögerte Freisetzung hindeutet. Darüber hinaus belegten die Ergebnisse, dass die Formulierung das Auge nicht reizte. Die AID-senkende Wirkung wurde hingegen nicht untersucht [85].

Alkholief et al. strebten in ihrer Studie an, eine optimale Formulierung für Dipivefrinhydrochlorid zu finden, ein Prodrug von Epinephrin, das in der Behandlung des Offenwinkelglaukoms eingesetzt wird [86]. Sie entwickelten Formulierungen mit Poloxameren ${ }^{\circledR}$ (P407 und P188) als gelbildenden Polymeren und Carbopol $^{\circledR} 934$ zur Erhöhung der Viskosität. In-vitro- und In-vivoTests bescheinigen der besten Formulierung ein geeignetes rheologisches Profil, die längste in vivo gemessene präkorneale Retentionszeit von $2 \mathrm{~h}$, eine verzögerte Wirkstofffreisetzung über 8 h sowie pharmakokinetische Parameter, die zu einer verbesserten Wirkstoff-BV im Vergleich zu konventionellen DipivefrinAugentropfen führen könnten [87].

\section{Xyloglucan}

Verschiedene Polysaccharide besitzen Potenzial für die Verwendung in Ophthalmika, z.B. Xyloglucan, Gellangummi (GG), Xanthan und Polygalakturonsäure. Zu den Vorteilen von Polysacchariden gegenüber synthetischen Polymeren zählen die einfache Gewinnung aus natürlichen Ressourcen, vielfältige Eigenschaften, niedrige Produktionskosten, Nichttoxizität und Biokompatibilität [88]. Xyloglucan, das aus Tamarindensamen gewonnen wird, zeichnet sich durch erhebliche Quellfähigkeit aus, was für die Herstellung der Bioadhäsion von Bedeutung ist. Darüber hinaus ermöglicht seine strukturelle Ähnlichkeit mit körpereigenem Muzin eine längere Adhäsion an der Augenoberfläche und somit eine verzögerte Wirkstofffreisetzung [89]. Für die Rolle von Xyloglucan bei der Verbesserung der Wirkstoff-BV spricht, dass es mit dem Wirkstoff makromolekulare ionische Komplexe bilden kann, so dass der Wirkstoff seine Wirkung länger ausüben kann als in konventionellen ophthalmischen Lösungen [62]. Aufgrund all dieser Eigenschaften wurde Xyloglucan zum Gegenstand von Studien, die darauf abzielen, Hindernisse für eine verlängerte Wirkstofffreisetzung und bessere BV von topischen Augenmedikamenten zu überwinden.

In der von Myjazaki et al. entwickelten Formulierung von Pilocarpinhydrochlorid wurde enzymatisch abgebautes Xyloglucan als Geliermittel verwendet. Der Vergleich der rheologischen Eigenschaften ergab für 2\% Xyloglucan eine äquivalente Gelstärke wie für 25\% PF-127. Xyloglucan bedeutet somit einen Fortschritt, da es in signifikant niedrigerer Konzentration in Formulierungen eingesetzt werden kann als PF-127. IGS mit Xyloglucan zeigten eine anhaltende Wirkstofffreisetzung über mehr als 6 h. Eine Formulierung mit 1,5\% Xyloglucan rief für eine Dauer von mindestens $4 \mathrm{~h}$ Miosis hervor, Gleiches galt für eine Formulierung mit 25\% PF-127 [91].

\section{Poly(N-isopropylacrylamid)}

PNIPAAm ist ein thermosensitives Polymer, das umfassend untersucht und in Wirkstoffabgabesystemen verwendet worden ist, da es bei Raumtemperatur in Wasser löslich ist. Außerdem lässt sich seine Geliertemperatur durch Copolymerisation z.B. mit Acrylsäure und PEO verändern [74].

PNIPAAm hat sich als guter Ansatz für die Verlängerung der Wirkstofffreisetzung im Auge erwiesen, hat jedoch den großen Nachteil, dass es einen starren und als unangenehm empfundenen Film auf der Hornhaut erzeugt. Dies ist eine von mehreren Hürden, die mit Formulierungen mit diesem Polymer verbunden sind und die Cao et al. durch die Entwicklung eines IGS mit PNIPAAm-Chitosan- (CS-)Derivat und Timololmaleat zu lösen versuchten. Im Vergleich zu herkömmlichen Timolol-Augentropfen erzielte dieses IGS eine stärkere AID-Senkung und eine längere Wirkungsdauer von bis zu $12 \mathrm{~h}$. Im Zytotoxizitätstest zeigte die Formulierung gute Verträglichkeit im Auge. Da die pharmakokinetischen Studien ihr im Vergleich zu herkömmlichen Augentropfen eine höhere Timololkonzentration im Kammerwasser $(11,2 \mathrm{ng} / \mathrm{ml}$ vs. $5,58 \mathrm{ng} / \mathrm{mL})$ und eine doppelt so hohe AUC bescheinigen, wird angenommen, dass diese Formulierung die BV im Auge verbessern kann [93].

Prasannan et al. entwickelten Augentropfen auf Basis eines Gelgemischs aus Poly(acrylsäure-graft-N-isopropylacrylamid) (PAA-graft-PNIPAAm) und PAA-co-PNIPAAm mit Epinephrin. Die Forscher wollten mit diesem Polymergemisch ein Problem bei der Applikation der Formulierung eines einfach quervernetzten Gels lösen, nämlich dass das System zu klein wird und es zu Wirkstoffverlust durch Abfluss kommt. Beim Gel mit nur PAA-graftPNIPAAm war eine schnellere Wirkstofffreisetzung zu beobachten, während das Gemisch aus PAA-graft-PNIPAAm und PAAco-PNIPAAm ein verzögertes Freisetzungsprofil zeigte. Der AID wurde für $36 \mathrm{~h}$ gesenkt, was eine erhebliche Wirkungsverlängerung im Vergleich zu der $8 \mathrm{~h}$ anhaltenden AID-Senkung nach Verabreichung von herkömmlichen Augentropfen darstellt. Darüber hinaus bildete sich nach der Applikation ein glatter Film, der bei den Versuchstieren keine Beschwerden verursachte. Die Ergebnisse zeigten außerdem, dass die Kinetik der Wirkstofffreisetzung aus den Polymer-Augentropfen durch die Dichte der Quervernetzung bestimmt wird [94].

Bellotti et al. arbeiteten daran, durch Polymerisation mit Polyethylenglykol (PEG) unter Verwendung von Brimonidintartarat als Wirkstoff die Geliertemperatur von PNIPAAm zu senken. Die Absenkung der Geliertemperatur soll verhindern, dass Gel-Augentropfen sich bei kaltem oder windigem Wetter wieder verflüssigen, und für eine rasche Gelierung nach der Verabreichung sorgen. Die Formulierung zeigte anhaltende Wirkstofffreisetzung über 28 Tage, wobei die Menge an Brimonidintartrat über die gesamte Studiendauer hinweg oberhalb der in der Literatur angegebenen minimalen Absorptionsgrenze lag. In Studien an menschlichen Bindehautepithelzellen zeigte die Formulierung keine $\mathrm{Zy}$ totoxizität [95].

\section{pH-sensitive IGS}

Alle $\mathrm{pH}$-sensitiven Polymere enthalten eine saure oder eine basische Gruppe, die in Reaktion auf eine Veränderung des pH-Wertes in ihrer Umgebung ein Proton aufnehmen bzw. abgeben kann.
50

Kompass Ophthalmol 2021;7:47-69 DOI: $10.1159 / 000516684$ 
Polymere mit mehreren solchen ionisierbaren Gruppen werden als Polyelektrolyte bezeichnet [98]. Die am häufigsten verwendeten $\mathrm{pH}$-responsiven Polymere in Ophthalmika sind PAA, Polycarbophil, CS und Celluloseacetatphthalat (CAP) [62].

In Ophthalmika mit hohem PAA-Gehalt $\left(\mathrm{Carbopol}^{\circledR}\right.$, Carbomer ${ }^{\circledR}$ ) könnte der niedrige pH-Wert der PAA-Lösung zur Schädigung der Augenoberfläche führen, bevor er durch die Tränenflüssigkeit neutralisiert wird [61]. Dieses Hindernis wurde überwunden, ohne die allgemeinen rheologischen Eigenschaften der Formulierung zu beeinträchtigen, indem PAA zum Teil mit HPMC oder anderen inerten, viskositätserhöhenden Polymeren kombiniert wurde [62].

Barse et al. entwickelten eine Formulierung mit Brimonidintartarat und einer Kombination aus Carbopol ${ }^{\circledR}$ 974P (0,45\%) und HPMC K4M (1\%). Dieses IGS sorgte für eine anhaltende Wirkstofffreisetzung über $8 \mathrm{~h}$, während konventionelle Augentropfen den Wirkstoff nur für $2 \mathrm{~h}$ abgaben, wie in-vitro-Freisetzungsstudien belegen. Ebenso wurde mit konventionellen Augentropfen der AID für $2 \mathrm{~h}$ um 13,38 $\pm 4,42 \%$ gesenkt, mit dem IGS hingegen für 8 h um 45,71 $\pm 4,72 \%$, wie eine in-vivo-Studie an WeißenNeuseeländer-Kaninchen mit einem Schiøtz-Tonometer ergab [99]. Pang et al. stellten IGS mit Brimonidintartarat (0,05\%, 0,1\% und $0,2 \%)$ sowie Carbopol ${ }^{\circledR}$ 974P (0,3\%) und HPMC K4M (6\%) her. Die Gele mit den niedrigeren Wirkstoffkonzentrationen $(0,05 \%$ und $0,1 \%)$ bewirkten eine signifikante Senkung des AID im Vergleich zu den konventionellen Augentropfen mit 0,2\%, wie eine in-vivo-Studie an Weißen-Neuseeländer-Kaninchen ergab. In-vivo-Untersuchungen zur Augenreizung mittels Draize-Verfahren ergaben, dass das IGS keine Reizung des Augengewebes hervorruft. In der histologischen Untersuchung der Kaninchenaugen zeigte sich normales und gesundes Augengewebe. Die in vivo gemessene präkorneale Verweilzeit betrug $3 \mathrm{~h}$ auf der Hornhautoberfläche und im Bindehautsack und war somit signifikant länger $(p<0,01)$ als die 30 min Verweilzeit, die mit konventionellen Augentropfen erreicht wurde. Dies belegt, dass es möglich ist, mit Gelen mit niedrigerem Brimonidintartratgehalt die systemische Absorption zu reduzieren und damit systemische Toxizität zu verhindern [100].

Gupta et al. entwickelten ein IGS mit 0,4\% Carbopol $^{\circledR} / 0,5 \%$ CS und Timololmaleat. Die Formulierung bewirkte eine verzögerte Wirkstofffreisetzung über $24 \mathrm{~h}$, wie in-vitro-Freisetzungsstudien ermittelt wurde. Die Messung des AID mit dem Schiøtz-Tonometer in In-vivo-Untersuchungen an Kaninchenaugen ergab stärker ausgeprägte und länger anhaltende Effekte auf den AID. Für das IGS wurde ein langsamerer Wirkungseintritt gefolgt von einer intensiven AID-Senkung verzeichnet. Die maximale AID-Senkung wurde nach $7 \mathrm{~h}$ erreicht, was signifikant langsamer war $(p<$ 0,$05 ; n=6$ ) als die $4 \mathrm{~h}$ bei der Liposomenformulierung bzw. 1,5 h bei den konventionellen Augentropfen. Die Autoren machten jedoch keine genauen Angaben zu den gemessenen AID-Werten. Dies ist ein eleganter Lösungsansatz, denn das Problem beim Einsatz von CS liegt darin, dass es sich beim pH-Wert des Auges in ein Hydrogel umwandeln kann. Das gebildete Gel bedarf jedoch weiterer Quervernetzung, damit ein Gel mit ausreichender me- chanischer Stabilität entstehen und der Wirkstoff kontrolliert freigesetzt werden kann. Die Strukturfestigkeit eines Polymers lässt sich steigern, indem man es mit anderen Polymeren mischt oder hydrophob modifiziert, was durch Zugabe von Carbopol ${ }^{\circledR}$ erreicht wurde [98].

Einen ähnlichen Ansatz, jedoch mit einem anderen Polymer, verfolgten Gupta et al., als sie eine mit Timololmaleat beladene, auf CS/HPMC basierende Polymermatrix entwickelten, um die Retention im Auge zu verbessern. Ihre Formulierung erwies sich als nicht bis leicht reizend, gut verträglich, mit verbesserter transkornealer Wirkstoffpermeation und verlängerter kornealer Retention dank der Viskosität und Bioadhäsivität des CS sowie mit anhaltender Wirkstofffreisetzung über $12 \mathrm{~h}$ [104].

Dexamethason ist ein Wirkstoff, der einerseits dank seiner Lipophilie leicht Membranen durchdringt, andererseits durch seine Hydrophobie in seiner klinischen Verwendbarkeit eingeschränkt wird. Um dieses Hindernis zu überwinden, verwendeten Kesavan et al. bei der Entwicklung ihres $\mathrm{pH}$-sensitiven IGS Hydroxypropyl$\beta$-cyclodextrin (HP- $\beta$-CD) als Lösungsvermittler und Penetrationsverstärker. Die optimierte Formulierung enthielt 0,2\% Carbopol $^{\circledR} 980 \mathrm{NF}$ und $0,4 \% \mathrm{NaCMC} \cdot$ In-vitro-Freisetzungsstudien belegen die anhaltende Freisetzung von Dexamethason über $12 \mathrm{~h}$ und somit signifikant langsamer $(p<0,01)$ als bei der auf dem Markt befindlichen Formulierung. In-vivo-Studien an Kaninchen ergaben signifikant weniger Entzündung bei den mit pHsensitivem IGS behandelten Tieren [106].

\section{Ionen-aktivierte IGS}

Auch das Vorliegen verschiedener Ionen $\left(\mathrm{Na}^{+}, \mathrm{K}^{+}, \mathrm{Ca}^{+}\right)$in der Tränenflüssigkeit kann einen Phasenwechsel in bestimmten Polymerdispersionen herbeiführen. Die anionische Natur dieser Polymere führt zu einer Anziehungswirkung zwischen dem Polymer und Ionen entgegengesetzter Ladung. Wenn sich diese Anziehungskräfte vereinen, induzieren sie eine Konformationsänderung in der Polymerstruktur, die zum Sol-Gel-Übergang der Polymerdispersion führt. Zwei der am häufigsten in der ophthalmischen Wirkstoffabgabe verwendeten ionensensitiven Polymere sind GG und Natriumalginat (SA) [74].

Die Gelierung von GG nimmt proportional zum Gehalt der Tränenflüssigkeit an ein- oder zweiwertigen Kationen zu. Dadurch steigt mit dem üblichen, reflexhaften Tränenfluss, der sonst zur Verdünnung viskoser Lösungen führt, die Viskosität der Formulierung, da mit dem Tränenvolumen auch die Menge an Kationen zunimmt [107].

Die optimale Brinzolamid-Formulierung in der Arbeit von Sun und Zhou hatte eine GG-Konzentration von 0,25\%. In-vitro-Freisetzungsprofile bescheinigen dem IGS die anhaltende Freisetzung von Brinzolamid. Das IGS gab den Wirkstoff über $12 \mathrm{~h}$ hinweg ab, verglichen mit $2 \mathrm{~h}$ bei konventionellen Augentropfen. Darüber hinaus rief das IGS weniger Reizung hervor als marktübliche Augentropfen, wie ein in-vivo-Irritationstest nach der DraizeMethode bei Kaninchen zeigte. Eine histologische Analyse wurde durchgeführt, um die langfristige Reizwirkung zu beurteilen. Abbildungen mikroskopischer Präparate zeigten eine zufriedenstel- 
lende Epithel- und Stromastruktur mit wenig Ödembildung nach Gabe von physiologischer Kochsalzlösung. Beim IGS hingegen zeigte sich leichte Ödembildung. Es bestand jedoch kein signifikanter Unterschied zwischen den beiden $\operatorname{Gruppen}(p<0,05)$. Die AID-senkende Wirkung hielt $6 \mathrm{~h}$ an, und ihr Profil unterschied sich von dem marktüblicher Augentropfen. Das IGS bewirkte eine AID-Senkung um 18,2\% nach $1 \mathrm{~h}$, gefolgt von einem langsamen Wiederanstieg auf $18,6 \mathrm{mmHg}$ und somit immer noch unter dem Ausgangswert nach 6 h. Die Augentropfen hingegen führten zur Senkung des AID um $27 \%$ nach 1 h, jedoch schneller Rückkehr auf das Ausgangsniveau nach $6 \mathrm{~h}(21,2 \mathrm{mmHg})$. Das IGS bewirkte eine signifikant stärkere $(p<0,05)$ AID-Senkung als konventionelle Augentropfen. Mit einem Tonometer wurden Dreifachmessungen des AID zu acht Zeitpunkten durchgeführt (0, 0,5, 1 , 2, 3, 4, 5 und $6 \mathrm{~h}$ ) [108].

Brinzolamid war auch der Wirkstoff der Wahl für Bhalerao et al. Das IGS auf GG-Basis, das sie damit herstellten, enthielt außerdem Dimethylsulfoxid als Co-Lösungsmittel für das Brinzolamid und Polyoxyl-35-Rizinusöl als Tensid, das den Bedarf an Dimethylsulfoxid verringern kann, ohne die Löslichkeit des Wirkstoffs zu beeinträchtigen. Das IGS zeigte im Vergleich zu konventionellen Augentropfen eine verlängerte Verweilzeit am Auge von 1624 h. Das IGS schien auch effektiver hinsichtlich der Tiefe und Dauer der AID-Senkung zu sein und rief zudem keine Augenreizung hervor [109].

In zahlreichen Studien sind Möglichkeiten untersucht worden, durch Kombination von Polymeren, die auf unterschiedliche Reize reagieren, neue IGS zu formulieren. Der Einsatz unterschiedlicher Kombinationen senkt nicht nur die benötigte Konzentration der einzelnen Polymere, sondern verstärkt auch das Ansprechen des Systems auf multiple Reize. Ein weiterer Schwerpunkt der Forschung liegt auf der Formulierung von reizsensitiven Polymeren als kolloidale Trägersysteme, z.B. Polymer-Mizellen, Nanosuspensionen oder lipidbasierte Nanocarrier. All das hat zu einer Steigerung der therapeutischen Wirksamkeit und Bioverfügbarkeit von Ophthalmika geführt [61, 62].

\section{Nanosysteme}

Natürliche, synthetische oder halbsynthetische Polymere können in Nanoformulierungen für die Glaukomtherapie integriert werden. Natürliche Polymere können anionisch, kationisch, amphipathisch oder neutral sein. Die wichtigsten anionischen Polymere sind Alginsäure, Carrageenan, Chondroitinsulfat, Dextransulfat und Hyaluronsäure. Ein Beispiel für ein kationisches Polymer ist CS; Kollagen, Fibrin und Gelatine sind amphipathisch; und zu den neutralen Polymeren zählt Dextran. Sie alle imitieren die extrazelluläre Matrix, können aber von Charge zu Charge variieren, immunogen wirken und Kreuzkontaminierung unterliegen. Synthetische Polymere hingegen haben eine festgelegte Struktur, leicht kontrollierbare Eigenschaften und keine immunogene Wirkung. Mit verschiedenen Methoden sind sie einfach zu verarbeiten. Aufgrund der unterlegenen mechanischen Eigenschaften der natürlichen Polymere einerseits und der schlechten Bioverträglichkeit der synthetischen Polymere andererseits sind Kombina-
tions-Polymere (natürlich-natürlich, natürlich-synthetisch und synthetisch-synthetisch) entwickelt worden, z.B. KollagenAcrylat und Alginat-Acrylat [117].

Kationische Lipid-Polymere neigen zur Interaktion mit dem negativ geladenen Hyaluronan im Glaskörperraum. Poly(styren)(PS-)Nanosphären traten mit Kollagen in der Sklera in Wechselwirkung, was in schlechter Diffusion durch den Glaskörperraum resultierte. Im Vergleich zu Nanopartikeln mit einem positiven Zeta-Potenzial von 11,7 mV diffundierten solche mit einem negativen Zeta-Potenzial von -33,3 mV leichter durch den Glaskörperraum. Zahlreiche Modifikationen wurden entwickelt, um diese Probleme zu überwinden, z.B. Maskierung der reaktiven Oberfläche der Nanopartikel, Targeting spezifischer Transporter oder Rezeptoren auf der Zelloberfläche oder PEG-Modifikation der Nanopartikel-Oberfläche [118]. Als anionisches Polymer kann Hyaluronsäure in ophthalmologischen Nano-Präparaten pharmakokinetische Wirkstoffeigenschaften verstärken, wenn es in Kombination mit entweder Methacrylsäureanhydrid oder Adipohydrazid verwendet wird. Die in solcher Weise funktionalisierte Hyaluronsäure wurde als Hydrogel formuliert, in das dann entweder ungebundener Wirkstoff oder wirkstoffbeladene Liposomen integriert werden können. Das resultierende Gel wird als hyaluronsäurebasiertes Nano-Composite-Hydrogel bezeichnet und ermöglicht eine kontrollierte Wirkstofffreisetzung $[119,120]$.

Die potenzielle lokale und systemische Toxizität von Nanopartikeln gilt es noch in präklinischen Studien zu untersuchen. Auch die bisherigen Studien zum Einsatz von Nanopartikeln in der Glaukomtherapie wurden mehrheitlich an Tieren durchgeführt. Klinische Studien sind erforderlich, um die tatsächliche Zytotoxizität, Verträglichkeit und Wirksamkeit der Nanopartikel-Therapien beim Menschen zu bestätigen. Mögliche Nebenwirkungen, die Nanopartikel hervorrufen könnten, sind zum Beispiel zelluläre Toxizität infolge von oxidativem Stress, Interaktion mit der Zellmembran oder Entzündungen [121]. Diese Nanotoxizität ist abhängig von der Partikelgröße, -form und -fläche, von der Molekülaggregation und -konzentration und vom Dosisschema [122]. In-vivo-ähnliche Nanotoxizitätsstudien an dreidimensionalen humanen Organen und Zellen werden an die Stelle der herkömmlichen in-vitro-Studien treten [123, 124]. Hier ist eine sorgsame Implementierung von Vorschriften erforderlich, und Forschende aus verschiedenen Fachgebieten von Pharmazie und Medizin über Technologie bis hin zur Biomedizintechnik sollten in die künftige Forschung einbezogen werden [126].

\section{Nanopartikel}

Verschiedene Arzneimittel zur Behandlung des Glaukoms sind bereits in Nanopartikel eingearbeitet worden (Abbildung 1B). Mit Hyaluronsäure modifizierte CS-Nanopartikel könnten ein vielversprechendes Wirkstoffabgabesystem zur Anwendung beim Glaukom darstellen [127].

Polymer-Nanopartikel verlängern die präkorneale Verweilzeit des Wirkstoffs; dies gilt insbesondere für CS, eins der natürlichen Polysaccharide mit mukoadhäsiven Eigenschaften. Es zeigt beDOI: $10.1159 / 000516684$ 
grenzte Löslichkeit in Wasser und bessere Löslichkeit in sauren Lösungen [128].

Li et al. haben mit Betaxolol beladene CS/Montmorillonit- (MT-) Nanopartikel mit einer Größe von $460 \pm 0,6 \mathrm{~nm}$ und einem ZetaPotenzial von $29 \pm 0,18 \mathrm{mV}$ entwickelt. Die Fläche unter der Kurve (AUC; area under the curve) und die mittlere Verweilzeit (MRT; mean residence time) waren 1,99- bzw. 1,75-mal höher als die der Betaxolol-Lösung. Somit erhöhten die CS/MT-Nanopartikel die BV des Wirkstoffs. In-vitro- und in-vivo-Studien ergaben eine verlängerte präkorneale Retentionszeit aufgrund des engen Kontakts mit dem negativ geladenen Muzin der Hornhaut. Mit Nanopartikeln konnten bei Kaninchen eine signifikante AID-Senkung und ein therapeutische Wirkung erzielt werden [129].

Warsi et al. formulierten mit Dorzolamid beladene Nanopartikel aus Poly(d,l-lactid-co-glycolid) (PLGA) von $129 \pm 12,3$ nm Größe mit Polyvinylalkohol (PVA) und Tocopheryl-PEG-1000-Succinat (TPGS) als Emulgatoren. Diese Formulierung passierte die Hornhaut in bis zu 2,5 mal höherem Maße als die konventionelle Lösung. Sie zeigte ein biphasisches Freisetzungsprofil: erst eine flutartige Ausschüttung von Wirkstoff (28,15-34,89\% über $1 \mathrm{~h}$, aufgrund der hydrophilen Natur des Wirkstoffs sowie der Wirkstoffadsorption an der Oberfläche), dann eine verzögerte Freisetzung (79,50-91,78\% über drei Tage). Nanopartikel mit TPGS bewirkten eine maximale AID-Senkung von $29,12 \%$ nach $4 \mathrm{~h}$; eine Senkung um 22,8\% wurde für $20 \mathrm{~h}$ aufrechterhalten. Bei Nanopartikeln mit PVA wurde eine maximale AID-Senkung von $22,8 \%$ nach 4 h erreicht, und eine Senkung um 16\% wurde für 16 $\mathrm{h}$ aufrechterhalten. Dies wurde in einer in-vivo-Studie an Kaninchen nachgewiesen. Beide Formulierungen waren sicher für die Anwendung im Auge und riefen keine Reizung hervor. Sie könnten die Adhärenz der Patienten verbessern und haben Potenzial gezeigt, dass hieraus Augentropfen entwickelt werden könnten, die man einmal täglich anwendet und die sicher für die Langzeitanwendung sind [130].

Khan et al. stellten mit CS beschichtete PLGA-Nanopartikel mit Forskolin mit einer Größe von 201,56 \pm 10,92 nm und einem Zeta-Potenzial von 10,1 $\pm 3,49 \mathrm{mV}$ her. Die Verwendung von sowohl PLGA (synthetisches Polymer) als auch CS (natürliches Polymer) trug dazu bei, eine bessere Permeation und Mukoadhäsivität auf der Hornhaut und Lederhaut zu erreichen. Der Wirkstoff wurde langsam abgegeben; nach $72 \mathrm{~h}$ waren $90 \%$ freigesetzt. Beide Polymere sorgten für die verzögerte Wirkstofffreisetzung und bewirkten eine länger anhaltende AID-Senkung. Seine maximale Wirkung entfaltete das Forskolin nach 8 h; hier lag der AID bei $16,3 \pm 0,75 \mathrm{mmHg}$ und damit signifikant unter dem Ausgangswert $(25,2 \pm 0,98 \mathrm{mmHg})$. Nach $24 \mathrm{~h}$ betrug der AID 20,6 $\pm 1,03$ $\mathrm{mmHg}$, wie eine in-vivo-Studie an Kaninchen ergab. Die lang anhaltende Wirkung wurde durch die CS-Beschichtung erreicht. Mit Forskolin beladene CS-PLGA-Nanopartikel können erfolgreich als Alternative zu konventionellen Darreichungsformen wie Augentropfen in der Behandlung des Glaukoms eingesetzt werden, da sie sich als nicht-reizend und gut verträglich erwiesen, ohne Anzeichen von Entzündung [132].
Bhagav et al. stellten mit Brimonidintartrat beladene Eudragit ${ }^{\circledR}$ Nanopartikel her, um ihre verzögerte Wirkstofffreisetzung im Kaninchenauge zu untersuchen. Eudragit ${ }^{\circledR}$-Nanopartikel sind inerte Polymer-Copolymere, die speziell für den Einschluss lipophiler Wirkstoffe entwickelt wurden. Formulierungen mit höherer PVA-Konzentration führten aufgrund der geringeren Nanopartikelgröße und größeren effektiven Oberfläche zu einer höheren initialen Wirkstoffausschüttung, während Formulierungen mit einer niedrigeren PVA-Konzentration eine langsamere Wirkstofffreisetzung zeigten. Bei der niedrigeren PVA-Konzentration waren die Nanopartikel größer und die Wirkstofffreisetzung entsprechend verzögert. Es waren keine Anzeichen von Augenreizung oder Toxizität festzustellen, und die AID-Senkung hielt länger an als bei den konventionellen Augentropfen. Die Adhärenz der Patienten lässt sich mit diesen Darreichungsformen steigern, weil die Glaukomtherapie weniger häufig verabreicht werden muss [133].

Lipide sind leicht verfügbar aus natürlichen Quellen, doch die negative Ladung von festen Lipid-Nanopartikeln (SLN; solid lipid nanoparticles) stellt ein Problem für die Wirkstoffpenetration und -absorption durch die Hornhautoberfläche dar. Daher hat man SLN mit kationischen Polymeren beschichtet, um die korneale Wirkstoffabsorption zu verbessern. Mit CS beschichtete und mit Methazolamid beladene SLN mit einer Größe von 188,2 bis 191,6 nm und einem Zeta-Potenzial von -8,1 bis -10,7 mV ermöglichen eine intensivere Behandlung des Glaukoms. Diese SLN wurden durch ein modifiziertes Emulsions-Lösungsmittel-Evaporationsverfahren hergestellt. Methazolamid, Lipidkomponente und Emulgator wurden bei $70^{\circ} \mathrm{C}$ in Ethanol gelöst, um eine ölige Phase zu erhalten. Die wässrige Phase mit Tween 80 und PEG 400 als Tensid bzw. Cotensid wurde auf die gleiche Temperatur erhitzt. Nach Zugabe der öligen in die wässrige Phase und Entfernung des organischen Lösungsmittels wurde diese Voremulsion in die kalte kontinuierliche Phase gegeben, und nach $2 \mathrm{~h}$ Rühren lagen SLN vor. Mit den beschichteten SLN wurde eine verzögerte Wirkstofffreisetzung und eine länger anhaltende AID-Senkung als mit unbeschichteten SLN oder auf dem Markt befindlichen Formulierungen erreicht. Die beschichteten SLN riefen keinerlei Reizung hervor. Eine weitere Möglichkeit zur Steigerung der Wirkstoffpenetration und -absorption liegt darin, bei der Formulierung von SLN kationische Lipide zu verwenden. In-vivo-Ergebnisse mit dieser Formulierung belegen, dass es möglich ist, im Vergleich zu konventionellen Augentropfen die Anwendungshäufigkeit pro Tag zu verringern und die Adhärenz der Patienten zu verbessern. Die Nanopartikel zeigten eine verzögerte Wirkstofffreisetzung. Nach 1 h hatten die SLN 77,34\% des Methazolamids freigesetzt. Die flutartige Freisetzung ist entweder auf die Dispersion von freiem Wirkstoff in die externe Phase oder die Verkapselung von Wirkstoff mit erhöhter Konzentration in der äußeren Hülle der SLN oder auf der Oberfläche der Nanopartikel zurückzuführen. Die große spezifische Oberfläche verstärkte noch die initiale Wirkstofffreisetzung. Durch das Vorliegen von Phospholipiden und Tensiden wurde die spezifische Oberfläche vergrößert und die Partikelgröße der Nanopartikel verkleinert. 
Die SLN hatten somit insgesamt eine große Oberfläche, was zu einer schnellen Wirkstofffreisetzung beitrug. Die AUC betrug nach 8 h 186,11-196,48, die MRT lag bei 5,16-5,28 h und die maximale AID-Senkung bei 35,69-36,66 $\mathrm{mmHg}$ [140].

\section{Nanoemulsionen}

Nanoemulsionen (Abbildung 1B) sind definiert als Emulsionen im Nanogrößenbereich; sie werden zur Verbesserung der Wirkstoffabgabe hergestellt. Sie sind thermodynamisch stabile, isotrope Systeme, in denen zwei nicht miteinander vermischbare Flüssigkeiten unter Verwendung eines Emulgators zu einer einzigen Phase vermengt werden [147]. Für die Anwendung beim Glaukom sind kationische Nanoemulsionen mit Acetazolamid besser geeignet als anionische oder neutrale Nanoemulsionen, da sie einen stärkeren Rückgang der Kammerwasserproduktion und eine entsprechend stärkere AID-Senkung bewirken. Die Tröpfchengröße lag im Bereich von 240-443 nm. Anionische Nanoemulsionen hatten ein negatives Zeta-Potenzial von -36,9 mV und kationische Nanoemulsionen ein positives Zeta-Potenzial von 41,4 mV, während ladungsneutrale Nanoemulsionen kein Zeta-Potenzial aufwiesen. Die Wirkstofffreisetzung aus kationischen Nanoemulsionen erfolgte langsamer als bei anionischen und neutralen Nanoemulsionen. Eine Erhöhung des Verdünnungsverhältnisses von 1:5 auf 1:40 bewirkte bei keiner der Emulsionen einen plötzlichen Anstieg der initial freigesetzten Fraktion nach 5 min. Jenseits der 5 min war ein progressiver Anstieg der Wirkstofffreisetzung zu beobachten. Mit Dorzolamidhydrochlorid gefüllte Nanoemulsionen zeigten stabile physikalisch-chemische Eigenschaften und wirkten nicht reizend. Die maximale AID-Senkung lag nach 0,51,6 h vor, und die Wirkung hielt bis zu 4-6 h an (21,63-37,23\%). Die AUC lag nach $10 \mathrm{~h}$ bei 85,49-130,53, und die MRT betrug 2,01-2,86 h, wie eine In-vivo-Studie an Kaninchen ergab. Nachgewiesen wurden außerdem ein schneller Wirkungseintritt und eine lang anhaltende Wirkung sowie eine damit verbundene Steigerung der BV. Diese Formulierung kann die Zahl der täglichen Anwendungen verringern und die Adhärenz der Patienten verbessern. Die Untersuchungen ergaben keine Reizung und keine Entzündung, was ebenfalls sehr vielversprechend ist [149].

\section{Nanosuspensionen}

Nanosuspensionen sind definiert als kolloidale Wirkstoffabgabesysteme, bei denen feste Partikel in einer flüssigen Phase dispergiert sind. Dank ihrer nicht-wasserlöslichen Eigenschaften sind sie gut in Hydrogele zu integrieren. Sie werden für die Verabreichung von lipophilen Wirkstoffen verwendet, um deren BV zu erhöhen [150]. Mit einer Nanosuspension von Coleonol wurde eine AID-Senkung um $31 \%$ erzielt, die bis zu $12 \mathrm{~h}$ und somit signifikant länger als bei konventionellen Formulierungen anhielt; dies wurde jedoch bisher nur in vitro nachgewiesen [151]. Nanosuspensionen mit Diclofenac, mit einer Partikelgröße von $105 \mathrm{~nm}$ und einem Zeta-Potenzial von $8 \mathrm{mV}$, verlängerten die Retentionszeit des Wirkstoffs und steigerten seine Penetration in Hornhautgewebe. Auf die anfängliche flutartige Abgabe des Wirkstoffs (47\% nach $30 \mathrm{~min}$ ) folgte eine verzögerte Freisetzung (73\% nach
$8 \mathrm{~h}$ ). Die AUC betrug 3,06 $\pm 0,57 \mu \mathrm{gh} / \mathrm{ml}$, mit einer maximalen Konzentration $\left(\mathrm{C}_{\max }\right)$ von $0,78 \pm 0,11 \mu \mathrm{g} / \mathrm{ml}$ und einer $\mathrm{t}_{\max }$ von 2 $\mathrm{h}$, wie eine in-vivo-Studie an Kaninchen ergab. 24 Stunden nach der Verabreichung lag keine Schädigung der Hornhaut, Bindehaut oder Iris vor, was darauf hindeutet, dass diese Formulierung Potenzial als okuläres Wirkstoffabgabesystem in der Behandlung des Glaukoms besitzt [152].

Ionenaustauscherharze (IER; ion exchange resins) sind Polymere mit Säuregruppen (Carbon- und Sulfonsäuren) als Kationenaustauscher oder basischen Gruppen (quartäre Ammoniumverbindungen) als Anionenaustauscher, die durch Abschirmung und kompetitive Bindung zum Schutz des Wirkstoffs beitragen. Eine mit Betaxolol beladene Nanosuspension mit IER ist zugelassen und auf dem Markt verfügbar. Das Kationenaustauscherharz mit 0,25\% Betaxolol verlängert die Verweilzeit des Wirkstoffs im Bindehautsack [153].

In einer Studie an Patienten mit entweder primärem Offenwinkelglaukom oder okulärer Hypertension wurde kein signifikanter Unterschied zwischen 0,5\%iger Betaxolol-Lösung und 0,25\%iger Betaxolol-Nanosuspension hinsichtlich der AID-Senkung festgestellt (3,6 mmHg vs. 3,3 mmHg), wobei jedoch die Nanosuspension mit signifikant weniger Augenbeschwerden einherging [154]. Nanosuspensionen könnten somit als Trägersysteme für lipophile Wirkstoffe zur Behandlung des Glaukoms wie z.B. Carboanhydrasehemmer ( CAI) eingesetzt werden [155].

\section{Liposomen}

Ein Liposom (Abbildung 1B) sind definiert als eine Doppelwand aus Phospholipiden, die mit dem menschlichen Körper biokompatibel ist und sowohl hydrophile als auch hydrophobe Wirkstoffe freisetzen kann [156, 157]. Liposomen können die BV von Wirkstoffen verbessern und für kontrollierte Wirkstofffreisetzung sorgen, da sie auf bestimmte Auslöser wie z.B. Temperatur, elektromagnetische Wellen oder $\mathrm{pH}$-Wert reagieren [158, 159]. Sie können sich auch mit der Zeit zersetzen, je nach Wanddicke, Zusammensetzung und Partikelgröße [160].

Die Oberflächenladung von Liposomen beeinflusst die Verweilzeit des Wirkstoffs. Die Oberfläche des Hornhautepithels ist wegen der darauf liegenden Muzinschicht negativ geladen; das begünstigt die Bindung von positiv geladenen Liposomen, verlängert ihre Verweilzeit und sorgt so für eine höhere Hornhautpermeation und Verkapselungseffizienz als bei negativ geladenen Liposomen. Neben positiv geladenen Liposomen zeigten auch neutrale Liposomen günstigere Eigenschaften als negativ geladene [161].

Ein potenzieller Nachteil von Liposomen ist ihre Tendenz zur Aggregatbildung, da diese zum Austritt von Wirkstoff führen kann. Auch sind Liposomen anfällig für den Prozess der Phagozytose. Die Modifikation der Oberfläche hat jedoch geholfen, diese Probleme zu überwinden. Bioadhäsive Polymere werden eingesetzt, um Liposomen zu beschichten und so ihre Aggregation zu verhindern und die Viskosität zu erhöhen [167].

Mit Latanoprost beladene Liposomen mit einer Größe von 103,18 $\pm 5,1 \mathrm{~nm}$ wurden sechs Personen, bei denen entweder eine okuläre Hypertension oder ein primäres Offenwinkelglaukom dia-
54

Kompass Ophthalmol 2021;7:47-69 DOI: $10.1159 / 000516684$ 
gnostiziert war, subkonjunktival verabreicht. Die Injektion wurde von allen sechs Personen gut vertragen. Der AID-Ausgangswert betrug 27,55 $\pm 3,25 \mathrm{mmHg}$; es wurde eine mittlere AID-Senkung von 13,03 $\pm 2,88 \mathrm{mmHg}$ bzw. 47,43 $\pm 10,05 \%$ erreicht. Nach drei Monaten lag eine klinisch und statistisch signifikante Reduktion des AID vor $(\geq 20 \%, p<0,05)$. Die anhaltende AID-senkende Wirkung ist zum Einen auf die Retention des Latanoprost in der Vorderkammer zurückzuführen, zum Anderen auf die verzögerte Wirkstofffreisetzung aus den Liposomen; es könnte aber auch sein, dass der gebundene Wirkstoff nur langsam aus dem Auge abtransportiert wurde [174].

\section{Niosomen}

Niosomen (Abbildung 1B) sind definiert als nicht-toxische, kugelförmige, geschlossene, doppelwandige Strukturen aus nichtionischen amphiphilen Bausteinen (Tensiden), die hydrophile und hydrophobe Wirkstoffe gleichermaßen und gleichzeitig abgeben können, was für eine Kombinationstherapie von Nutzen sein könnte. Sie bewirken eine verbesserte BV der Wirkstoffe und positives Ansprechen auf die Therapie $[175,176]$.

Mit Timolol beladene und mit CS beschichtete Niosomen von 2-3 $\mu \mathrm{m}$ Größe resultierten in einer 1,7-fach höheren $C_{\max }$ und 2,34mal größeren AUC im Kammerwasser im Vergleich zur TimololLösung. Das Timolol wurde aus den Niosomen langsam freigesetzt und verblieb länger im Kammerwasser, sodass eine effektive Hemmung der Kammerwasserproduktion erreicht wurde; darauf folgte ein Anstieg der Timololkonzentration (Sekundärpeak), da das Kammerwasservolumen erheblich abnahm. Das in einer Lösung verabreichte Timolol wurde rasch ausgewaschen und zeigte einen deutlich kleineren Sekundärpeak. Die Verwendung der Niosomen ging mit weniger systemischen Nebenwirkungen einher $[177,178]$. Auch mit Acetazolamid beladene Niosome zeigten eine verlängerte Wirkstofffreisetzung im Auge. Bei Verwendung von Niosomen wurde eine maximale AID-Senkung von $3 \mathrm{mmHg}$ erreicht (7\% mehr als bei Verwendung einer Acetazolamid-Suspension), und die Wirkung hatte bis zu $5 \mathrm{~h}$ Bestand. Bei bioadhäsiv beschichteten Niosomen blieb die maximale Wirkung bis zu 6 $\mathrm{h}$ aufrechterhalten. Die beschichteten Niosomen bewirkten eine AID-Senkung um 33\%, die unbeschichteten Niosomen um 30\%. Für die bioadhäsiv beschichtete Formulierung betrug die $\mathrm{C}_{\max }$ $14,94 \mu \mathrm{g} / \mathrm{ml}$, die $\mathrm{t}_{\max } 100 \mathrm{~min}$. und die AUC 1.230,0116 $\mu \mathrm{gmin} / \mathrm{ml}$ [179]. Multilamellare Niosomen können eine höhere Wirkstoffdosis einschließen und diese über einen längeren Zeitraum freisetzen [180].

\section{Dendrimere}

Dendrimere (Abbildung 1B) sind laut Definition biokompatible und nicht-immunogene polymere Materialien mit flexibler Verzweigung und großer Oberfläche [181, 182].

Für hybride Poly(amidoamin)- (PAMAM-)Dendrimer-Hydrogel-PLGA-Nanopartikel mit einem Acrylat-tragenden PEG zur gleichzeitigen Gabe von zwei bewährten Wirkstoffen der Glaukomtherapie, Brimonidin und Timolol, wurde nachgewiesen, dass sie keine zytotoxischen Effekte hervorrufen und eine anhal- tende AID-Senkung und lange Retentionszeit mit verzögerter Wirkstofffreisetzung bewirken und so die okuläre BV über sieben Tage im Kammerwasser in Kaninchenaugen verbesserten, verglichen mit Kochsalzlösung als Kontrolle [184].

Mit Carteolol beladene Dendrimere mit einer Carboxyl-Endgruppe und quartärem Ammoniumsalz zeigten eine längere Verweilzeit und keine Augenreizung in Kaninchenaugen; dies spricht für eine mögliche Verringerung der Dosierungshäufigkeit. Die Wirkstoff-BV im Kammerwasser war 2,5-mal höher als bei der konventionellen Lösung [182].

\section{Cyclodextrin-Komplexe}

Cyclodextrine sind definiert als zyklische Oligosaccharide, d.h. einer ringförmigen Struktur aus Zuckermolekülen. Man unterscheidet $\alpha$-, $\beta$ - und $\gamma$-Cyclodextrine mit 6-, 7- bzw. 8-gliedrigen Ringen [188]. Ihr Vorteil liegt darin, dass sie einen Wirkstoff abgeben können, ohne dessen molekulare Struktur zu verändern. Cyclodextrine sind an der Oberfläche hydrophil; damit kann also ein eingeschlossener lipophiler Wirkstoff die hydrophile Barriere des Auges passieren und die lipophile Hornhautoberfläche erreichen, um dann ins Kammerwasser freigesetzt zu werden [67].

Dorzolamid mit $\gamma$-Cyclodextrin zeigte eine verlängerte Verweilzeit im Kammerwasser und könnte als einmal tägliche Formulierung verwendet werden. Der Komplex hatte eine Größe von 5,4 $\mu \mathrm{m}$. Die $\mathrm{C}_{\max }$ betrug $5,4 \mu \mathrm{g} / \mathrm{ml}$ und die $\mathrm{t}_{\max } 4 \mathrm{~h}$. Die anhaltende Freisetzung von Dorzolamid wurde ebenso nachgewiesen wie anhaltend hohe Dorzolamid-Konzentrationen im Kammerwasser für bis zu $24 \mathrm{~h}$. Hieraus lässt sich schließen, dass der Komplex aus Dorzolamid und $\gamma$-Cyclodextrin das Potenzial hat, eine der besten Formulierungen für die Anwendung dieses Wirkstoffs im Auge zu sein [189].

Propylamino- $\beta$-Cyclodextrin bewirkte eine signifikante Verbesserung der Löslichkeit und Stabilität von Latanoprost in vitro und 6\% weniger Augenreizung und entzündliche gemischtzellige Infiltrate in vivo, verglichen mit der auf dem Markt befindlichen Formulierung. Durch Komplexbildung aus Latanoprost und Propylamino- $\beta$-Cyclodextrin konnte die Löslichkeit von Latanoprost erhöht und so ein potenzieller Wirkstoffverlust im Zuge der Adsorption an der Oberfläche vermieden werden. Diese Formulierung rief weniger Augenreizung hervor als die auf dem Markt befindlichen Latanoprost-Formulierungen und verbesserte zugleich die Wirkstoffabgabe durch Verlängerung der Retentionszeit von Latanoprost, wie eine in-vivo-Studie an Kaninchen ergab. Latanoprost und Propylamino- $\beta$-Cyclodextrin zeigten bessere okuläre Verträglichkeit als die auf dem Markt erhältliche Formulierung. Dies ist eine vielversprechende Lösung für die Langzeitbehandlung des Glaukoms, insbesondere im Hinblick auf eine verbesserte Adhärenz der Patienten [194].

\section{Nanokristalle}

Nanokristalle sind definiert als feste Partikel mit einem Durchmesser von weniger als $1 \mu \mathrm{m}$ und kristalliner Struktur. Sie sind aus einem Wirkstoff und einem kristallinen Überzug zusammengesetzt [195]. Ohne weitere Trägermaterialien vermögen sie eine 
effektive Oberfläche und gute Wirkstoff-BV zu gewährleisten. Nanokristalle sind durch eine schnelle initiale Auflösung gekennzeichnet, was auf eine bessere Wirkstoff-BV hindeutet, doch innerhalb von $1 \mathrm{~h}$ lösen sich alle Nanokristalle auf, was mit der kommerziellen Formulierung kompatibel ist [196].

\section{Nanodiamanten}

Nanodiamanten (Abbildung 1B) sind definiert als kohlenstoffbasierte Nanopartikel mit einer trunkiert-oktaedrischen Struktur im Größenbereich von 2-10 nm [200]. Auf ihrer Oberfläche sind viele funktionelle Gruppen kovalent oder nicht-kovalent gebunden. So kann zum Beispiel ihre mit Polyethylenimin (PEI) beschichtete Oberfläche mit $\mathrm{N}$-acetyliertem CS konjugiert und mit Timolol beladen werden, um ein Nanogel in Form von Kontaktlinsen (KL) herzustellen. Auf diese Weise kann eine anhaltende Wirkstofffreisetzung erreicht werden, da das CS in Gegenwart von Lysozym dissoziiert. Nanodiamanten geben den KL auch mechanische Unterstützung [201].

\section{Okuläre Inserte}

Eine der größten Herausforderungen bei der Formulierung von Inserten ist ihre Form, da diese die Wirkstoff-Beladungskapazität ebenso beeinflusst wie die Retention und den Tragekomfort. Bisher ist nicht abschließend geklärt, welche Form bei okulären Inserten funktional die beste ist, doch es wurde bei menschlichen Probanden nachgewiesen, dass stäbchenförmige Produkte am besten toleriert werden [202].

Der erste Bericht über okuläre Inserte aller Art behandelte ein kleines Stück Filterpapier, das mit einer Wirkstofflösung (Atropinsulfat oder Pilocarpinhydrochlorid) getränkt war [203]. Bei den okulären Inserten (Abbildung 1C) unterscheidet man lösliche und nicht-lösliche Systeme; zusätzlich haben einige Autoren den Begriff «bioerodierbar» als dritte Kategorie eingeführt. Andere Autoren erachten zwar löslich und bioerodierbar für dasselbe, doch weisen die beiden wesentliche Unterschiede auf, da ihnen unterschiedliche chemische Prozesse zugrunde liegen [204]. Die Klassifizierung beruht auf den Polymeren, die bei der Formulierung der okulären Inserte zum Einsatz kommen. Die am häufigsten in diesen Produkten verwendeten Polymere sind MC und seine Derivate, HPMC, Ethylcellulose (EC), Polyvinylpyrrolidon (PVP), Polyvinylalkohol (PVA), CS und seine Derivate, Gelatine und verschiedene Gemische dieser Polymere [205]. Bisher wurden die meisten Produkte für die posteriore Wirkstoffabgabe, z.B. AID-senkende Arzneimittel für die Glaukombehandlung, erforscht [202].

Ein Beispiel für einen nicht-löslichen okulären Inert ist Ocusert ${ }^{\circledR}$ (Alza Corporation Inc., Vacaville, CA, USA), das von Armaly und Rao entwickelt wurde (Abbildung 1C). Hier ist Pilocarpin in einen Kern aus Alginatgel eingearbeitet, der als zentrales Reservoir von einer mikroporösen Membran aus Ethylen-Vinylacetat-Copolymer umgeben ist. Durch diese Membran diffundiert das Pilocarpin in kontrollierter Weise $[206,207]$. Ocusert ${ }^{\circledR}$ wurde wegen zu starker initialer Wirkstofffreisetzung und Dislokation des Inserts vom Markt genommen [202].
SODI (Soluble Ophthalmic Drug Inserts) sind ovale Plättchen aus Polyacrylamid, Vinylpyrrolidon und Ethylacrylat-Copolymeren, die von Maichuk entwickelt wurden. Nach Einlegen in den Bindehautsack erweicht das SODI und verwandelt sich nach 60-90 min. Kontakt mit dem Tränenfilm in eine viskose Polymerlösung. Darin enthaltener Wirkstoff wird über 34-72 h freigesetzt [208]. Das Produkt wurde aus unbekannten Gründen vom Markt genommen [202].

Reservoir-Inserte mit Brimonidintartrat wurden erfolgreich mittels Lösungsmittel-Gießtechnik formuliert, wobei 1,4 1\% Celluloseacetatbutyrat (CAB) als ratenkontrollierende Membran und 5\% HPMC als Reservoirfilm verwendet wurden. PEG-600 wurde in der Formulierung als Weichmacher verwendet, in einer Konzentration von $60 \%$ des Trockengewichts von CAB. Die Formulierung zeigte eine kontrollierte Wirkstofffreisetzung über $24 \mathrm{~h}$, mit einer exzellenten Korrelation von in vivo zu in vitro, da der AIDsenkende Effekt ebenfalls $24 \mathrm{~h}$ anhielt. Die Inserte hatten eine akzeptable Dicke, d.h. sie waren nicht augenreizend laut Augenreizungstest, und sie zeigten eine gute Stabilität und physikalische Integrität [209].

Biologisch abbaubare okuläre Inserte, die durch LösungsmittelGießtechnik aus 7\% PVP K-90 und 1,5 \% niedermolekularem SA mit einseitiger EC-Beschichtung hergestellt wurden, vermochten die Freisetzung von Brimonidintartarat in vitro für $24 \mathrm{~h}$ aufrechtzuerhalten. Ihre therapeutische Wirksamkeit in Bezug auf die AID-Senkung war der von konventionellen BrimonidintartratAugentropfen überlegen. Die Dauer der AID-Senkung entsprach mit $7 \mathrm{~h}$ zwar nicht den in-vitro-Ergebnissen, stellte aber dennoch eine verzögerte Wirkstofffreisetzung dar. Diese Formulierung verursachte bei der Applikation leichten Tränenfluss, jedoch keine Rötung. Dies könnte durchaus ein vielversprechender Ansatz sein, wie die Autoren sagen, allerdings bleibt die Frage, ob es für den Patienten praktikabel ist, alle $7 \mathrm{~h}$ einen Arzt aufzusuchen, damit dieser das nächste Insert einlegen kann [210].

Okuläre Inserte nur mit CS werden für verschiedene Wirkstoffe zur Glaukombehandlung entwickelt, z.B. für Bimatoprost [212], Brimonidintartarat [213] und Diminazen [214], außerdem in Kombination mit Hydroxyethylcellulose für Dorzolamid [215] und in Kombination zu gleichen Teilen mit Chondroitinsulfat für Diminazen [216].

\section{Ocufit SR ${ }^{\circledR}$ System}

Das Ocufit SR ${ }^{\circledR}$ System (Abbildung 1C) ist ein Wirkstoff freisetzendes, stäbchenförmiges ophthalmologisches Produkt, das in die untere und obere Umschlagfalte eingelegt werden kann [202]. Das zylindrische Stäbchen, das in Form und Größe an die Umschlagfalte des menschlichen Auges angepasst ist, wurde aus einem Silikonelastomer hergestellt und mit Timolol beladen. Eine Studie ergab, dass die Positionierung des Systems im oberen Bindehautsack zu einer erhöhten okulären Wirkstoffaufnahme führt [204].

\section{Topisches ophthalmisches Wirkstoff-Applikationssystem}

Das von Amorphex Therapeutics (Andover, MA, USA) entwickelte Topical Ophthalmic Drug Delivery Device (TODDD ${ }^{\mathrm{TM}}$ ) ist ein
56

Kompass Ophthalmol 2021;7:47-69 DOI: $10.1159 / 000516684$ 
weiches, biegsames, topisches System aus klarem Elastomermaterial, das unter dem oberen Augenlid in Kontakt mit der Bindehaut getragen wird (Abbildung 1C). Es liegen Berichte zu präklinischen Untersuchungen zu TODDD ${ }^{\mathrm{TM}}$ mit Timolol, Prostaglandine oder einer Kombination daraus vor; demzufolge können die Systeme mehrere Wirkstoffe abgeben und eine kontinuierliche Abgabe über bis zu 90 Tage gewährleisten. Leahy et al. untersuchten die Wirksamkeit eines TODDD ${ }^{\mathrm{TM}}$ mit Timolol bei normotensiven Kaninchen. Sie stellten fest, dass die maximale AID-Senkung über den gesamten dreimonatigen Versuchszeitraum hinweg Bestand hatte [217]. Eine weitere präklinische Studie an acht Beagle-Hunden zu einem TODDD ${ }^{\mathrm{TM}}$ mit Latanoprost ergab eine AID-Senkung, die mit der von Timolol vergleichbar war. Jedoch waren hier die Retentionsraten gering; am Ende des 16-tägigen Studienzeitraums waren nur drei Systeme noch an ihrem Platz, was allerdings an der Nickhaut, dem dritten Augenlid der Tiere, liegen könnte. Es lässt sich nicht mit Sicherheit sagen, ob es auch beim Menschen so wäre. In beiden Studien waren keine systemischen Wirkstoffkonzentrationen nachzuweisen [218].

\section{Topischer okulärer Ring}

Eine interessante Form von okulären Inserten ist der topische okuläre Ring (Abbildung 1C). Hierbei handelt es sich um eine konservierungsmittelfreie Formulierung, bei der 13 mg Bimatoprost in eine Silikonmatrix eingearbeitet werden, welche wiederum über eine innen liegende Polypropylen-Trägerstruktur gezogen wird. Auf diese Weise werden Ringe von 24-29 mm Durchmesser hergestellt. Wie schnell das Bimatoprost in den Tränenfilm abgegeben wird, wird durch die physikalischen Eigenschaften des Silikons, die Oberfläche der Silikon-Wirkstoff-Matrix sowie die Bimatoprost-Konzentration in der Silikon-Wirkstoff-Matrix bestimmt. Sechs Monate lang gaben die Bimatoprost-Inserte den Wirkstoff in abnehmender Menge ab, von etwa $35 \mathrm{mg}$ täglich (an Tag 0) bis 6 mg (an Tag 180). In Formulierungstests wurde untersucht, ob auch Travoprost oder Latanoprost in die Silikonmatrix integriert werden können. Da der Ring im Vergleich zu anderen Systemen zur verzögerten Wirkstofffreisetzung ein großes Volumen hat, können damit auch zwei Wirkstoffe verabreicht werden, z.B. Bimatoprost und Timolol. Darüber hinaus haben klinische Studien bestätigt, dass die Anwendung dieses Rings eine sechs Monate lang anhaltende AID-Senkung bewirkt. Der Ring hat sich als sicher und gut verträglich erwiesen. Er ist in verschiedenen Größen erhältlich, sodass man die richtige Größe für jeden Patienten auswählen kann, und er zeigt hervorragende primäre Retentionsraten $[219,220]$.

\section{Punctum Plugs}

Punctum Plugs (PP) blockieren den Tränenkanal und verhindern so den Abfluss der natürlichen Tränenflüssigkeit von der Augenoberfläche (Abbildung 1C). In den letzten zehn Jahren sind verschiedene feste oder halbfeste Ausführungen entwickelt worden, die zusätzlich zur Wirkstofffreisetzung in der Lage sind. Unter anderem in der Glaukombehandlung lässt sich damit eine anhaltende Wirkstofffreisetzung für bis zu vier Monate erreichen. Sie basieren auf dem Grundgedanken, dass bei blockiertem Tränenabfluss lokal verabreichte Tropfen nicht so schnell das Auge verlassen können, sodass die Verweilzeit und die Penetration des Wirkstoffs gesteigert und dadurch seine Wirksamkeit verbessert wird. PP sind einfach einzubringen und dadurch als Wirkstoffabgabesystem weithin akzeptiert. Bei einigen Patienten kann jedoch auch ein Fremdkörpergefühl nach der Applikation ein erhebliches Hindernis darstellen. PP können entweder als Hilfsmittel zur Blockade des Tränenabflusses oder als Wirkstoffabgabesystem eingesetzt werden. Je nach verwendetem Material kann man zwischen semipermanenten und temporären PP unterscheiden. Silikon, Teflon $^{\circledR}$, Hydroxyethylmethacrylat (HEMA), Polycaprolacton (PCL) oder Polydioxanon werden am häufigsten für semipermanente PP verwendet, während tierisches Kollagen und verschiedene Polymere für temporäre PP genutzt werden. Semipermanente $\mathrm{PP}$ werden spontan oder durch einen Arzt entfernt. Temporäre PP hingegen werden immer spontan entfernt, indem sie sich innerhalb von drei Tagen bis sechs Monaten (je nachdem, aus welchem Material sie bestehen) auflösen [221]. Der größte Nachteil von PP ist, dass sie aufgrund ihrer Größe nur mit sehr begrenzten Wirkstoffmengen beladen werden können [202].

Die Wirksamkeit der PP als Hilfsmittel wurde von Opitz et al. bestätigt, die einen zusätzlichen AID-senkenden Effekt bei Anwendung von PP in Verbindung mit Travoprost-Monotherapie nachwiesen [222]. Sherwin et al. gelangten zu ähnlichen Ergebnissen bei Patienten, die verschiedene AID-senkende Wirkstoffe anwendeten, darunter auch Fixkombinationen mit Prostaglandinanaloga [223]. Was die Nutzung von PP als Wirkstoff-Trägersystem angeht, so lassen sie sich auf zwei Arten mit Wirkstoff beladen. Der Wirkstoff kann sich entweder unter einer undurchlässigen Schicht im Kern befinden, aus dem es durch einen Einschnitt herausdiffundiert. Oder die Plugs werden mit Wirkstofflösung beschichtet [221].

Travoprost PP, entwickelt von Ocular Therapeutix Inc. (Bedford, MA, USA), ist ein stäbchenförmiger PP aus Poly(milchsäure)(PLA-)Mikrosphären mit verkapseltem Travoprost, eingebettet in eine getrocknete PEG-Hydrogelmatrix. Die bioresorbierbaren Mikrosphären werden durch Hydrolyse in der Tränenflüssigkeit langsam abgebaut und geben dabei 90 Tage lang Wirkstoff ab. Dieses System ist mit einer visuellen Hilfe ausgestattet, um die Visualisierung nach der Platzierung zu ermöglichen [224, 225]. Mati Therapeutics entwickelte ein L-förmiges PP mit Latanoprost, bei dem der Wirkstoff eingebettet in ein Polymergemisch (Evolute ${ }^{\circledR}$-Plattform) in einem Reservoir vorliegt. Nach Kontakt mit dem Tränenfilm wird der Wirkstoff über drei Monate durch eine Öffnung freigesetzt $[221,226]$.

\section{Kontaktlinsen}

Die Möglichkeit, Kontaktlinsen (KL; Abbildung 1D) als Wirkstoffabgabesysteme zu nutzen, ist ebenfalls in zahlreichen Studien untersucht worden. Einige davon haben ergeben, dass weiche KL eine anhaltende Wirkstofffreisetzung ermöglichen, eine große Herausforderung bei der Formulierung aber darin liegt, dass sie transparent bleiben müssen, um die Sicht nicht zu behindern. 
Weiche KL sind ein Netzwerk, das infolge der Vernetzung von wasserlöslichen polymeren Hydrogelen entsteht. Viele verschiedene Polymere kommen bei ihrer Herstellung zum Einsatz [202, 207, 226].

Die erste Studie zu KL in der Behandlung des Glaukoms geht auf das Jahr 1974 zurück, als Hillman KL aus Vinylpyrrolidon-/AcrylCopolymer drei Tage lang in 1\%igen Pilocarpin-Augentropfen tränkte. Die AID-senkende Wirkung war äquivalent zu der einer 4\%igen Pilocarpin-Lösung [229]. Ein neuerer Ansatz basiert auf der Verkapselung einer Timolol-Mikroemulsion in Linsen aus Poly-2-hydroxyethylmethacrylat- (p-HEMA-)Hydrogel; hiermit lässt sich eine Timolol-Freisetzung über acht Tage erreichen [230]. Für eine besser kontrollierte Wirkstofffreisetzung aus der mit Timolol-Mikroemulsion beladenen p-HEMA-Linse formulierten Li et al. eine Mikroemulsion von Ethylbutyrat in Wasser und stabilisierten diese mit PF-127 als Tensid. Diese Variante zeigte jedoch nicht den gewünschten Effekt; das in-vitro-Freisetzungsprofil in phosphatgepufferter Kochsalzlösung ergab eine schnelle Freisetzung von Timolol im Vergleich zu entionisiertem Wasser [231]. Eine Verbesserung des Ansatzes bestand darin, KL mit Vitamin E zu beladen, da Vitamin E nachweislich die Dauer der TimololFreisetzung verlängert [232]. Peng et al. verwendeten ACUVUE ${ }^{\circledR}$ TruEye $^{\mathrm{TM}}$ Linsen (Johnson \& Johnson Vision Care, Inc., Jacksonville, FL, USA), bei denen ein innovatives Design für hohen Tragekomfort und eine konstante Befeuchtung der Oberfläche sorgt, sodass die Linse im klinischen Einsatz vom Komfort her mit dem Nichttragen von Linsen vergleichbar ist [233]. Die Linsen wurden erst in einer Lösung mit Vitamin-E-Ethanollösung und dann in einer Timololmaleat-Lösung in Phosphatpuffer getränkt. In-vivo-Ergebnisse zeigten, dass das kontinuierliche Tragen von ACUVUE $^{\circledR}$ TruEye $^{\mathrm{TM}}$ Linsen (Johnson \& Johnson Vision Care, Inc., Jacksonville, FL, USA) mit 20\% Vitamin E zu einer signifikanten Senkung des AID führen kann. Die Drucksenkung hatte fünf Tage Bestand, obwohl das Arzneimittel nicht über den vierten Tag hinaus verabreicht wurde - dies könnte auf eine Akkumulation und nachfolgende Freisetzung des Wirkstoffs im Augengewebe zurückzuführen sein. Es wurden keine Beschwerden oder Anzeichen von okulärer Toxizität beobachtet [234].

Latanoprost-eluierende KL wurden von Ciolino et al. entwickelt, indem sie Latanoprost-PLGA-Filme mittels Polymerisation mit ultraviolettem Licht in Methafilcon-Linsen einkapselten [236]. Methafilcon-Linsen bestehen aus einem Copolymer aus HEMA und Methacrylsäure [237]. In-vitro- und in-vivo-Studien belegen eine rasch einsetzende und danach einen Monat lang anhaltende Wirkstofffreisetzung [236].

Fünf handelsübliche Silikon-KL - ACUVUE ${ }^{\circledR}$ ADVANCE $^{\mathrm{TM}}$ und ACUVUE $^{\circledR}$ OASYS $^{\text {TM }}$ (Johnson \& Johnson Vision Care, Inc., Jacksonville, FL, USA), NIGHT \& DAY ${ }^{\mathrm{TM}}$ (Alcon, Fort Worth, TX, USA), O2OPTIX ${ }^{\mathrm{TM}}$ (Alcon, Fort Worth, TX, USA) und PureVision $^{\mathrm{TM}}$ (Bausch \& Lomb, Bridgewater, NJ, USA) - wurden in einer Studie verwendet, um die Dauer der Dexamethason-Freisetzung zu erhöhen, indem die KL mit Vitamin E beladen wurden. Im Gegensatz zu hydrophilen Wirkstoffen, bei denen Vitamin E in KL eine hydrophobe Diffusionsbarriere darstellt, wird die Diffusion des hydrophoben Dexamethasons durch die Viskosität von Vitamin E reduziert. Die Vitamin-E-Beladung der KL erfolgte durch Tränken der Linsen in ethanolischer Vitamin-E-Lösung und nachfolgende Evaporation des Ethanols. Die Beladung der KL mit $30 \%$ Vitamin E verlängerte die Freisetzung von Dexamethason auf 7-9 Tage und somit eine 9- bis 16-mal so lange Zeit wie bei KL ohne Vitamin E. Ein weiteres wichtiges Ergebnis dieser Studie ist, dass Vitamin E die Dexamethason-Freisetzung in den ersten $5 \mathrm{~h}$ um mehr als $25 \%$ reduzierte [240].

Zudem wurde nachgewiesen, dass sich durch Verwendung von hydrophoben KL eine bessere Kontrolle der Dexamethason-Freisetzung erreichen lässt. In einer Studie von Behl et al. wurden durch ionische Gelierung synthetisierte CS-NP mit Dexamethason beladen und in Hydroxymethacrylat-Ethylenglykol-Dimethacrylat-KL eingearbeitet. KL, die mit $200 \mu \mathrm{g}$ NP beladen waren, zeigten 95\% optische Klarheit bei einer über 10 Tage kontinuierlich ansteigenden Dexamethason-Freisetzung und Abgabe der Gesamtmenge über 22 Tage; die BV war 72\% höher als bei konventionellen Augentropfen [241]. Weitere Studien zur Zytotoxizität und zur Wirkung in vivo stehen noch aus, doch diese Formulierung löst das Problem der anhaltenden Dexamethason-Freisetzung und bietet dadurch erhöhten Patientenkomfort zur Erhöhung der Adhärenz.

\section{Corneal Shields aus Kollagen}

Aus Kollagen bestehende Corneal Shields (CCS) sind KL-ähnliche Inserte aus Kollagen bovinen oder porcinen Ursprungs. Sie werden durch Tränken in einer Lösung mit Wirkstoff imprägniert. Ihre ursprünglichen Anwendungsgebiete sind die Behandlung nach einem Trauma sowie der Schutz der Hornhaut. Für die Behandlung von chronischen Erkrankungen sind sie nicht sinnvoll, da sie ihre Wirkung über mehrere Tage entfalten. Das würde bei chronischen Erkrankungen, wie z.B. dem Glaukom, einen häufigen Linsenaustausch bedeuten, was weder für den Patienten noch für den Arzt praktikabel ist. Nach dem Einlegen in das Auge lösen sich CCS auf und bilden eine viskose Schutzschicht, die die Hornhautoberfläche bedeckt und dadurch schützt. Die Kollagenmatrix fungiert zugleich als Reservoir, in dem ein Wirkstoff reversibel gebunden vorliegt. Der Wirkstoff wird allmählich freigesetzt; dadurch wird auch einer systemischen Toxizität vorgebeugt. CCS werden in dehydrierter Form hergestellt und müssen vor der Anwendung befeuchtet werden [242, 243].

\section{Okuläre Implantate}

Okuläre Implantate (Abbildung 1E) als Wirkstoffabgabesysteme können aus Polymeren, Edelstahl oder anderen Metallen bestehen und biologisch abbaubar oder nicht biologisch abbaubar sein. Biologisch abbaubare Implantate können aus PLGA, Silikon oder PLA bestehen. Sie werden im Auge nach einiger Zeit abgebaut und resorbiert. Nicht biologisch abbaubare Implantate hingegen müssen durch einen Eingriff entfernt werden, der Komplikationen nach sich ziehen kann. Der Vorteil dieser Art von Implantaten ist jedoch eine längere Wirkstofffreisetzung. Sie können aus Metallen oder Polymeren wie PVA oder Ethylen-Vinyl-Alkohol bestehen [245]. Kim et al. entwickelten ein Implantat mit dem Prosta-
58

Kompass Ophthalmol 2021;7:47-69 DOI: $10.1159 / 000516684$ 
glandinanalogon DE-117. Der Wirkstoff ist hier zwischen zwei PCL-Filmschichten eingeschlossen. PCL ist ein biologisch abbaubares Polymer, das die Wirkstoffdiffusion begrenzt und bei dieser Formulierung eine verzögerte Wirkstofffreisetzung über sechs Monate ermöglicht [246].

Die Allergan plc (Dublin, Irland) hat das Produkt Bimatoprost SR entwickelt; ein biologisch abbaubares Implantat, das über sechs Monate verzögert Bimatoprost freisetzt. Das enthaltene Bimatoprost liegt im biologisch abbaubaren Wirkstoffabgabesystem NOVADURTM vor (Abbildung 1E). Das NOVADURTM-System basiert auf Polyglactin-PLGA, das leicht modifiziert ist, um eine gleichmäßige Freisetzung von Bimatoprost für bis zu sechs Monate sicherzustellen [247]. Das Unternehmen arbeitet außerdem an der Entwicklung eines NOVADURTM-Wirkstoffabgabesystems mit Brimonidin [248].

Die PolyActiva Pty Ltd. (Parkville, Australien) hat ein stäbchenförmiges Latanoprost-Implantat entwickelt, das für mindestens sechs Monate ab dem ersten Tag nach dem Einsetzen eine konstante Tagesdosis Latanoprost abgibt. Das Implantat ist darauf ausgelegt, dass es nach Behandlungsende so schnell wie möglich in sichere und ungiftige Nebenprodukte biologisch abgebaut wird, ohne Rückstände zu hinterlassen. Das Implantat besteht aus einem einzigen Biomaterial (Latanoprost, polymeres Prodrug der freien Säure) auf Basis des Polytriazol-Hydrogelsystems von PolyActiva. Die Sicherheit dieses Implantats wurde in einer Sicherheitsstudie der Phase Ia nachgewiesen und wird derzeit in einer klinischen Studie der Phase Ib geprüft [249].

Samy et al. entwickelten ein PCL-Implantat, das eine Kombination aus Timolol und Brimonidin abgibt. Zwei PCL-Dünnschicht-Taschen - eine mit Timolol beladen und eine mit Brimonidin - werden hierbei miteinander verbunden und bilden so ein V-förmiges System zur kombinierten Wirkstoffabgabe. In-vitro-Freisetzungstests ergaben eine anhaltende Freisetzung beider Wirkstoffe über 60 Tage. Eine in-vivo-Studie belegt eine AID-Senkung über 13 Wochen [250]. Das Titanimplantat iDose ist mit einer Travoprost-Formulierung befüllt und von einer Membran bedeckt, durch die der Wirkstoff langsam in die Vorderkammer des Auges abgegeben wird. Die Wirksamkeit der Behandlung mit dem iDose wurde in einer randomisierten klinischen Phase-II-Studie mit der von Timolol-Lösung verglichen; das Implantat erwies sich als der herkömmlichen Lösung überlegen. Das iDose zeigt Wirkstofffreisetzung und AID-Senkung über 12 Monate; das ist mehr als bei jedem anderen neuartigen Wirkstoffabgabesystem. Sein Hauptnachteil ist jedoch, dass es nicht biologisch abbaubar ist und chirurgisch entfernt werden muss, nachdem der gesamte Wirkstoff freigesetzt wurde. Die Studie bescheinigt dem iDose auch ein günstiges Sicherheitsprofil, ohne Nebenwirkungen wie Hyperämie [225, 251]. Ein weiterer interessanter Ansatz zur Behandlung des Glaukoms ist der Einsatz von Mikropumpen, der von Replenish, Inc. (Pasadena, CA, USA) unter dem Markennamen Ophthalmic MicroPumpTM System kommerziell entwickelt wurde. Das Sortiment umfasst vier Produkte: Anterior MicroPump ${ }^{\mathrm{TM}}$ für Patienten mit Glaukom, Posterior MicroPump ${ }^{\mathrm{TM}}$ für Patienten mit Netzhauterkrankungen, EyeLink ${ }^{\mathrm{TM}}$ und Drug Refill System ${ }^{\mathrm{TM}}$. Eine Pumpe wird direkt in das Auge implantiert. Das Arzneimittel wird über einen Port in ein Reservoir injiziert und von dort über ein Kanülensystem abgegeben. Die Rate der Wirkstofffreisetzung und die Dosierungshäufigkeit werden über das EyeLink ${ }^{\mathrm{TM}}$ gesteuert, ein drahtloses Programmier- und Ladegerät für die bidirektionale Kommunikation mit MicroPump ${ }^{\mathrm{TM}}$-Implantaten.

Das Drug Refill System ${ }^{\mathrm{TM}}$ ist eine separate Konsoleneinheit zum Befüllen und Nachfüllen von MicroPump ${ }^{\mathrm{TM}}-$ Implantaten mit einem Arzneimittel. Mit einem Einweg-Nachfüllschlauch-Set mit 31-Gauge-Nadel werden die Implantate (nach)befüllt [252].

Eine der Lösungen für Probleme mit der Formulierung von Dexamethason entwickelte die Allergan plc (Dublin, Irland) in Form des von der FDA und der Europäischen Arzneimittelagentur zugelassenen intravitrealen Dexamethason-Implantats Ozurdex ${ }^{\circledR}$. Dieses Implantat ist zur Einbringung in die vordere und hintere Augenkammer bestimmt und kann zur erfolgreichen Behandlung des Glaukoms beitragen, da das Glaukom sowohl als anteriore als auch als posteriore Augenerkrankung angesehen wird - anterior, weil das Therapieziel die Senkung des AID in der Vorderkammer ist, und posterior, weil die Therapie die Neuroprotektion des Sehnervs anstrebt [253].

Das System wird durch Zweifach-Schmelzextrusion hergestellt; dabei entstehen bioerodierbare Mikrosphären aus biologisch abbaubarem PLGA-Copolymer und mikronisiertem Dexamethason. Diese Implantate werden durch eine kleine Inzision in der Sklera mit einer dünnen Hohlnadel ins Auge eingebracht. Das System zeigte im Untersuchungszeitraum von 45 Tagen eine anhaltende Freisetzung in vitro [253] und erwies sich als therapeutisch wirksam über 6-9 Monate [254].

Es ist nachweislich wirksam, sicher und gut verträglich [255], mit der Einschränkung, dass es nur minimale Wirkstoffkonzentrationen in der Vorderkammer erzeugt und potenziell Komplikationen hervorrufen kann, z.B. erhöhten AID und Netzhautablösung [256] sowie Keratitis infolge einer Herpes-simplex-Virus-Reaktivierung nach der Implantatinjektion [257].

AGV war ein weiteres Substrat für die Filmschichtung in der Arbeit von Ponnusamy et al. Diese Arbeitsgruppe entwickelte ein System mit 5-FU und/oder MMC in PLGA-Film, der dann auf AGV geschichtet wurde. Sie nutzten einen sehr interessanten Ansatz der Filmherstellung in Form der «Breath Figure»-Methode, einem einfachen Verfahren zur Herstellung einer regelmäßigen Anordnung der Poren in einem Polymerfilm, bei dem das Lösungsmittel unter feuchten Bedingungen verdampft und eine Struktur ähnlich einem Bienenwabenmuster hinterlässt [259, 260]. Dieser Lösungsansatz ist insofern hervorhebenswert, weil die Autoren davon ausgingen, dass die poröse Struktur sowohl für die kontrollierte Wirkstoffabgabe als auch für den Abbau des Polymers von Vorteil wäre. Um eine kontinuierliche Freisetzung zu erreichen, stellten sie zweischichtige poröse PLGA-Filme her, bei denen in der unteren Schicht 5-FU dispergiert und auf die obere Schicht MMC aufgebracht wurde. So konnte von beiden Antifibrotika eine geringere Dosis verwendet werden. Das System war so konzipiert, dass es eine geringe Dosis MMC als initialen Burst abgab, um die Infiltration von Immunzellen unmittelbar nach 
dem chirurgischen Eingriff zu begrenzen, und dann langsamer, aber über einen längeren Zeitraum das weniger starke 5-FU, um die Fibroblastenproliferation zu hemmen. Mit Beginn der 5-FUFreisetzung setzte der Abbau des PLGA ein. Die Ergebnisse der Studie zeigten, dass die Inhibition des Fibroblastenwachstums 3-4 Wochen nach der Operation anhielt und in dieser Zeit der Großteil der Wundheilung ablief [261].

\section{Mikronadeln}

Mikronadeln (MN) sind minimal-invasive Systeme der dritten Generation, die ursprünglich zur Verbesserung der transdermalen Applikation verschiedener Wirkstoffe entwickelt wurden. Bei der Anwendung von MN wird die Hornschicht perforiert, wobei es zu begrenzter Interaktion mit Schmerzrezeptoren (Nozizeptoren) in der Dermis kommt [262-264]. Die Systeme besitzen nadelartige, massive oder hohle Spitzen in Mikrometergröße (25-2000 $\mu \mathrm{m})$ und können aus unterschiedlichsten Materialien hergestellt werden, z.B. Silizium, Edelstahl, Keramik, Glas, Zucker, Metall oder Polymeren [263-265].

Nachdem MN für die transdermale Wirkstoffgabe bereits umfassend untersucht sind, sind sie seit Kurzem auch für die gezielte transsklerale Verabreichung von therapeutischen Substanzen in das Augengewebe in der Diskussion [262]. Erste Studien haben bestätigt, dass MN die erfolgreiche Einbringung der Wirkstoffe sowohl in das hintere als auch in das vordere Augensegment ermöglichen. Sie sind ausreichend lang, um okuläre Barrieren wie die epitheliale Transportbarriere und den konjunktivalen Clearance-Mechanismus zu umgehen und ermöglichen die intrasklerale und intrastromale Wirkstoffgabe bei minimiertem Potenzial für Netzhautschäden [264, 266]. Somit gewährleisten sie eine gezielte Einbringung von Arzneimitteln ins Augengewebe, sodass die Wirkstoffe allein durch Diffusion an ihren Wirkort gelangen können (Abbildung 1F) [266].

Für eine effektive Glaukombehandlung müssen die Wirkstoffe die Tränenflüssigkeit, die Hornhaut und die Bindehaut durchdringen [265], zugleich gilt es, die Risiken bzw. Komplikationen, die mit intravitrealen Injektionen assoziiert sind - wie Katarakt, Blutungen, (Pseudo-)Endophthalmitis und Netzhautablösung -, zu reduzieren [267]. Das Design von MN ermöglicht eine hygienische, sichere, anwenderfreundliche und minimalinvasive Applikation ohne Schädigung der tieferen Augengewebe, da sie nur wenige hundert Mikrometer in die Sklera eindringen [117]. Sie geben das Arzneimittel in die Sklera oder in den Raum zwischen Sklera und Aderhaut ab, der ebenfalls das Auge umschließt und als suprachoroidaler Raum (SCS) bezeichnet wird [267]. Während in der Literatur insgesamt fünf Typen von $\mathrm{MN}$ beschrieben werden, konzentriert man sich bei der Anwendung am Auge hauptsächlich auf drei [264, 265, 268]:

- Beschichtete MN - perforieren das Augengewebe, innerhalb von Minuten löst sich das Arzneimittel auf, und nach kurzer Zeit wird die MN wieder entfernt [266]

- Hohl-MN - hier wird die effektive Wirkstoffapplikation im Augengewebe aus einem externen Reservoir durch passive Diffusion oder Druck ermöglicht [269-272]
- Sich auflösende Polymer-MN - bestehen aus einer löslichen Matrix, die sich nach der Verabreichung vollständig auflöst [273].

Diese drei MN-Typen ermöglichen eine schnelle Wirkstoffabgabe und Wiederentnahme der Nadeln oder ihrer Basis und imitieren so die Anwendung von herkömmlichen Injektionsnadeln. Solide wie hohle MN können zur Verabreichung verschiedenster Arzneimittel verwendet werden, einschließlich Nano- und Mikropartikel, Depot-Gels oder Wirkstofflösungen [264]. Der Erfolg dieser Injektionsbehandlung hängt davon ab, dass die Wirkstoffe an ihren jeweiligen spezifischen anatomischen Wirkort gelangen, was eine konstante Wirkstoffapplikation in kleineren Dosen ermöglicht als z.B. bei topischen Augentropfen, die zu mehr als 95\% gar nicht ins Auge aufgenommen werden und nur zu einem sehr geringen Anteil in den Ziliarkörper vordringen [274]. MN erscheinen daher als vielversprechende Strategie zur Behandlung nicht nur des Glaukoms, sondern auch anderer Augenkrankheiten.

Solide MN bilden vorübergehend Mikrokanäle, um die Permeabilität für den Wirkstoff zu erhöhen bzw. freie oder verkapselte Wirkstoffe, Peptide oder Impfstoffe einzubringen. Allerdings bestehen solide MN aus Edelstahl und Silikon und sind somit nicht biologisch abbaubar. Daher sind weitere präklinische Studien erforderlich, um ihre Sicherheit und Wirksamkeit für die Einbringung von Arzneimitteln ins Auge zu beurteilen [117, 268].

Khandan et al. stellten gefensterte Titan-MN her, um eine sichere, einfache und zuverlässige okuläre Arzneimittelapplikation bei gleichmäßiger Beschichtung mit dem Arzneimittel zu erreichen. Sie gingen davon aus, dass die optimale Dosis Pilocarpin für einen Monat nur $150 \mu \mathrm{g}$ beträgt, was einer signifikanten Dosisreduktion durch Verwendung von MN entspricht [266].

Meist wird bei soliden MN die Oberfläche mit einer Arzneimittelformulierung beschichtet [267]. Die Anwendung dieser MN erzeugt mikrometergroße Poren in der Leder- oder Hornhaut, die eine effektive Einbringung des Arzneimittels ermöglichen und die Freisetzung der Wirkstoffe aus der Beschichtung fördern (Abbildung 2) [268, 275].

Jiang et al. berichteten über die Anwendung von Pilocarpin-beschichteten MN im vorderen Augenabschnitt. Diese Art der Mikronadeln, die 500-700 $\mu \mathrm{m}$ lang sind, erhöhte die Absorptionsrate von Pilocarpin etwa um das 45-Fache. Die Ergebnisse belegen die exzellente Penetration der MN in die Sklera (bis zu $300 \mu \mathrm{m}$ ) und eine schnelle Auflösung und Abgabe der Wirkstoffe ins Auge. Die MN bewirkten eine schnelle und umfangreiche Verengung der Pupille von 8 auf 5,5 $\mathrm{mm}$ Durchmesser innerhalb von 15 min, während bei topischer Pilocarpin-Gabe lediglich eine Verengung auf $7 \mathrm{~mm}$ erreicht wurde [275].

Hohle MN ermöglichen die schnelle Verabreichung von Arzneimitteln in verschiedenen Formulierungen an eine bestimmte Stelle im Auge durch das Lumen der MN [268]. Mehrere Studien berichten über die minimalinvasive Arzneimittelapplikation mittels hohler MN in Augengewebe wie SCS, Sklera oder andere [277, 278]. Durch die Krümmung der Hornhaut können MN auf unterschiedliche Weise und in unterschiedlicher Tiefe in das Auge ein-
60

Kompass Ophthalmol 2021;7:47-69

DOI: $10.1159 / 000516684$ 


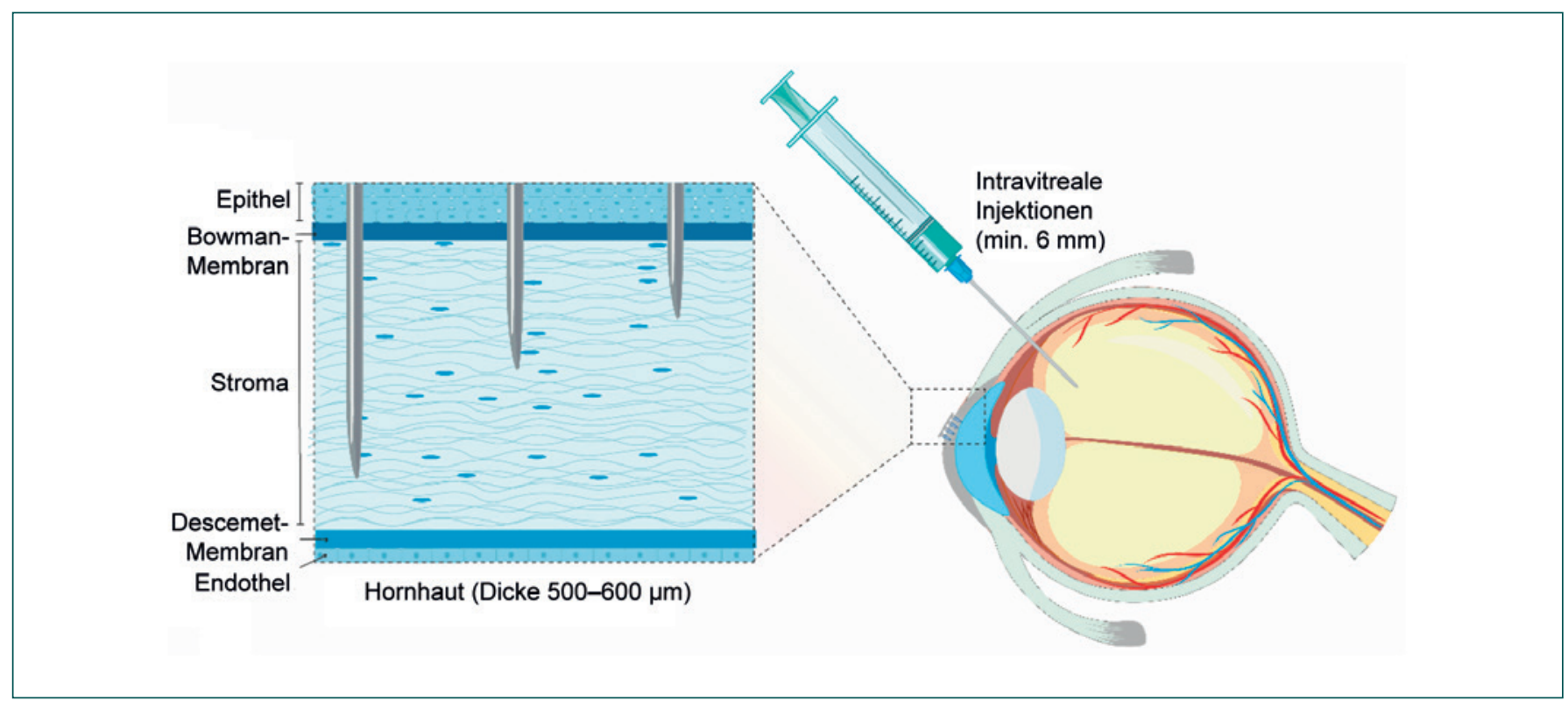

Abb. 2. Okuläre Anwendung von Mikronadeln (MN) und intravitrealen Injektionen im Vergleich. Durch die Länge der MN und die Krümmung der Hornhaut können alle Gewebestrukturen erreicht werden. Bei der intravitrealen Injektion hingegen muss die Nadel mehr als 6 mm tief in den Glaskörper eingestochen werden [276].

dringen und so eine vollständige Wirkstofffreisetzung in allen Hornhautstrukturen ermöglichen [262]. Sie können aus Borosilikatglas oder biologisch abbaubarem Polymer hergestellt werden. Erstere sind jedoch nicht für die klinische Anwendung geeignet [268]. Hohle MN ermöglichen die Applikation von Arzneimitteln zur Behandlung des Glaukoms [268].

Jiang et al. fertigten hohle MN, mit denen sie verschiedene Formulierungen mit Modellwirkstoff (Sulforhodamin), Nanopartikeln und Mikropartikeln in das Skleragewebe infundierten. Die Mikronadeln wurden $700-800 \mu \mathrm{m}$ tief in das Gewebe eingebracht, dann wurde die Arzneimittellösung mit einem Druck von $103,4 \mathrm{kPa}$ infundiert. Mit nachfolgendem Zurückziehen um 200 $300 \mu \mathrm{m}$ erreichten sie die erfolgreiche Abgabe von 10-35 $\mu \mathrm{l}$ Lösung in die Sklera, was auf die Bildung eines intraskleralen Wirkstoffdepots hindeutet. Die Abgabe von Mikropartikeln erfolgte allerdings nur in Gegenwart von Hyaluronidase und Kollagenase als Ausbreitungsfaktoren, die Komponenten des Gewebes abbauen [278].

Um Probleme in Bezug auf die Herstellung und Genauigkeit sowie Schwierigkeiten bei der Injektion der Arzneimittellösung aus beschichteten und hohlen MN zu überwinden, wurden sich auflösende polymere $\mathrm{MN}$ aus biologisch abbaubaren, biokompatiblen Polymeren für die okulare Wirkstoffabgabe vorgeschlagen. Die MN werden appliziert, dann werden die in die Polymermatrix eingearbeiteten Wirkstoffe ins Augengewebe abgegeben [283].

Roy et al. entwickelten ein Augenpflaster mit sich auflösenden Mikronadeln (550 $\mu \mathrm{m}$ Länge) nach Art einer handelsüblichen Kontaktlinse, das der Verabreichung von Pilocarpinhydrochlorid diente. Sie stellten fest, dass MN aus PVA und PVP sich sofort nach der Applikation auflösten und für einen signifikant höheren Pilocarpin-Fluss sorgten als Pilocarpin-Lösung [284].
Alles in allem ist festzuhalten, dass $\mathrm{MN}$ viele Vorteile gegenüber einer intravitrealen Injektion hat, bei der ganz durch die Lederhaut, Aderhaut und Netzhaut in den Glaskörper gestochen wird. MN dringen gezielt bis in die Sklera vor und vermeiden so die Komplikationen, die mit konventionellen ophthalmologischen Therapiestrategien verbunden sind (Abbildung 2). MN könnten auch zur Selbstverabreichung geeignet sein; in diesem Fall wäre die Glaukomtherapie lediglich einen Routinebesuch beim Arzt erfordern.

Kurz gesagt wächst das Interesse an diesem Gebiet, da MN auf minimalinvasive Weise für die Verabreichung verschiedenartiger Wirkstoffe, nicht nur von Glaukomtherapien, verwendet werden und sowohl für eine schnelle als auch für eine kontrollierte Wirkstofffreisetzung sorgen können. Das Gewebetrauma nach einer MN-Applikation ist zwar deutlich geringer ist als das Loch, das eine intravitreale Injektion hinterlässt, dennoch sind weitere Studien erforderlich, um mehr über den Mechanismus und die Dauer der Erholung zu erfahren.

Weitere Studien sollten sich der Herstellung von MN mit kostengünstigen, massentauglichen Fertigungsmethoden sowie der Entwicklung geeigneter Applikationssysteme für das Auge widmen. Erst wenn Sicherheitsstudien zu MN und Applikationskräften, Gewebetypen, Eindringtiefen, Formulierungsarten sowie geeigneten Tiermodellen vorliegen, können MN alle regulatorischen Hürden überwinden. Insgesamt scheint es, dass $\mathrm{MN}$ die okuläre Wirkstoffgabe in Zukunft revolutionieren werden.

\section{Okuläre lontophorese}

Die Iontophorese ist ein nicht-invasives Verfahren, das ermöglicht, bei Anwendung im vorderen oder hinteren Augensegment eine größere Wirkstoff-BV zu erreichen als mit der topischen An- 
wendung herkömmlicher Formulierungen. Dieses Verfahren ist zugleich sicherer als die konventionelle Dosierung, die mit systemischer Absorption oder intravitrealen Injektionen einhergeht und zu entsprechenden Nebenwirkungen und Infektionen führen kann. Die Wirkstoffapplikation basiert auf dem Prinzip der anziehenden oder abstoßenden Ladungen. Dies ermöglicht eine verbesserte Penetration des geladenen Wirkstoffs durch biologische Membranen und die Abgabe von positiv oder negativ geladenen Substanzen in das Zielgewebe (Abbildung 1G).

Wie viel Wirkstoff ins Auge gelangt, lässt sich auf zwei Arten steuern: (1) durch die Stärke des Stroms und (2) durch die Dauer der Anwendung. So wird im Auge eine therapeutische Wirkstoffkonzentration erreicht, und gleichzeitig können durch die minimale systemische Absorption systemische Nebenwirkungen vermieden werden $[285,286]$.

Das EyeGate II Delivery System (EGDS), das von der Eyegate Pharmaceuticals, Inc. entwickelt wurde, ist ein neuartiges okuläres Iontophorese-System, das alle genannten Vorteile auf sich vereint. Es besteht aus einem Applikator, der auf der Bindehaut aufliegt, und einem Generator, der mit einer Elektrode verbunden ist, die an der Stirn des Patienten befestigt ist (Abbildung 1G).

Der Generator erzeugt im Applikator ein elektrisches Feld und die entgegengesetzte Ladung an der Elektrode. Im Applikator befindet sich das Arzneimittel. Während der Dauer der elektrischen Stimulation wird das Arzneimittel durch die Hornhaut oder die Lederhaut geleitet. Das EGDS befindet sich derzeit noch in der klinischen Prüfung, zeigt aber vielversprechende Ergebnisse in der Behandlung von Erkrankungen des vorderen Segments und großes Potenzial für Erkrankungen des hinteren Segments. Die zukünftige Forschung wird sich besonders mit der Frage beschäftigen, ob das EGDS für den Einsatz bei potenziell zur Erblindung führenden Erkrankungen des hinteren Segments geeignet ist [287].

\section{Ausblick}

Zukunftsperspektiven für die Modulation der Wundheilung Da bei der Wundheilung verschiedene Wachstumsfaktoren eine zentrale Rolle spielen, ist eine der Richtungen, die bei der Entwicklung von Wirkstoffabgabesystemen zur Verhinderung der Vernarbung eingeschlagen werden, die Hemmung von Wachstumsfaktoren. Einige solche Ansätze wurden bereits postuliert und untersucht.

TGF- $\beta$ ist an der Wundheilung beteiligt, insbesondere an der Narbenbildung nicht nur in der Haut, sondern im gesamten Körper. TGF- $\beta 2$ ist seine im Auge vorherrschende Isoform und spielt eine Schlüsselrolle bei der Vernarbung der Bindehaut, weshalb es eins der Ziele bei der Modulation der Wundheilung ist, seine Produktion zu hemmen [288]. Decorin ist ein natürlich vorkommender TGF- $\beta$-Inhibitor und gilt daher im Vergleich zu klinisch geprüften monoklonalen Antikörpern gegen TGF- $\beta$ (CAT152) als sicherer [289], wobei unseres Wissens bisher keine Studie zur Anwendung von Decorin beim Menschen durchgeführt worden ist [33], jedoch erscheint eine Formulierung als sehr attraktive Option.
CAT-152 (Lerdelimumab) ist ein humaner monoklonaler Immunglobulin-G4-Antikörper, der TGF- $\beta 2$ neutralisiert, was bedeutet, dass er zu therapeutischen Zwecken eingesetzt werden kann, um die Narbenbildung zu hemmen. Angesichts ermutigender Ergebnisse aus klinischen Studien der Phase I und II wurde eine Phase-III-Studie zu CAT-125 bei 388 Patienten mit diagnostiziertem primärem Offenwinkelglaukom oder chronischem Engwinkelglaukom durchgeführt. Die Teilnehmer erhielten drei subkonjunktivale Injektionen mit CAT-152. Der erste Dosis wurde präoperativ in ca. $1 \mathrm{~cm}$ Entfernung vom Limbus corneae appliziert. Die zweite und dritte Dosis wurden unmittelbar nach der Operation bzw. am Tag danach injiziert. Die Auswertung ergab keine statistisch bedeutsamen Unterschiede zwischen den Behandlungsgruppen hinsichtlich des Behandlungserfolgs ( $p=$ 0,22294). Zudem war bei Patienten, die postoperativ 5-FU erhielten, um eine beginnende Narbenbildung zu verhindern, ein Behandlungserfolg weniger wahrscheinlich $(p=0,0003)$. Bei den Patienten mit primärem Offenwinkelglaukom war jedoch eine höhere Rate an Behandlungserfolgen zu verzeichnen als in den anderen Gruppen ( $p=0,0077)$ [290].

Die Inhibition von VEGF sorgt auch nach Glaukomoperationen für weniger Narbenbildung. Tier- und Humanstudien haben gezeigt, dass subkonjunktivale Injektionen mit Bevacizumab, einem monoklonalen humanisierten Antikörper gegen VEGF, die Narbenbildung wirksam reduzieren [291-294]. Vandewalle et al. führten eine einjährige randomisierte Studie an 138 Patienten mit nicht medikamentös kontrolliertem Offenwinkelglaukom durch. Den Teilnehmern wurden 1,25 mg/0,05 ml Bevacizumab intrakameral verabreicht, um zu untersuchen, ob diese Injektion das Ergebnis einer primären Trabekulektomie verbessern könnte. Die Ergebnisse dieser Studie belegen einen signifikant niedrigeren AID ein Jahr nach der Operation, jedoch ohne signifikanten Unterschied zwischen den Behandlungsgruppen $(p=0,69)$. Der absolute Erfolg war allerdings bei den mit Bevacizumab vorbehandelten Patienten besser $(p=0,02)$, was darauf hindeutet, dass es als adjuvante Therapie zur Verbesserung von Operations-Outcomes eingesetzt werden kann [295]. Diese Ergebnisse stehen in Korrelation mit anderen Studien [291, 295-297], die ergeben haben, dass Bevacizumab eingesetzt werden kann, um die Inzidenz von Versagen des Sickerkissens nach einer Trabekulektomie zu reduzieren. Hierzu ist auch der Bericht von Akkan und Cilsim interessant, die in einer 12-monatigen Nachbeobachtungsstudie bei 42 Patienten eine bessere Kontrolle des AID bei Werten unter $12 \mathrm{mmHg}$ verzeichneten, wenn nach der primären Trabekulektomie MMC topisch angewendet wurde als wenn Bevacizumab subkonjunktival gegeben wurde. Außerdem wurde in der Bevacizumab-Gruppe bei mehr Patienten der Einsatz von Glaukommedikation erforderlich [298]. Ähnliche Ergebnisse erbrachte eine randomisierte Studie mit 34 Patienten mit unkontrolliertem Glaukom erzielt. Nilforushan et al. verglichen, ob es das Outcome nach Trabekulektomie verbessert, wenn Bevacizumab oder MMC angewendet wird. Sie verzeichneten nach sechs Monaten eine AID-Senkung um 34 und $56 \%$ in der Bevacizumab- bzw. MMC-Gruppe. Eine bessere Kontrolle des AID wurde durch die Gabe von MMC erreicht [299].
62

Kompass Ophthalmol 2021;7:47-69 DOI: $10.1159 / 000516684$ 
In diesem Bereich sind jedoch weiterführende Studien erforderlich, zum Beispiel zu Fragestellungen im Zusammenhang mit der Wirkungsdauer und zu toxischen Auswirkungen auf das Hornhautendothel, die Linse und das Trabekelwerk. Außerdem muss untersucht werden, ob es Anti-VEGF-Wirkstoffe gibt, mit denen sich alle VEGF-Isomorphe auf einmal blockieren lassen [300].

Da Bevacizumab bisher nur für die Krebstherapie zugelassen ist und noch nicht für den postoperativen Einsatz, eröffnen sich hier ganz neue Möglichkeiten in den Bemühungen, ein für das Auge optimales Abgabesystem mit diesem Wirkstoff zu entwickeln. Vor diesem Hintergrund entwickelten Giannos et al. eine neuartige, stabilisierte Formulierung, die die Aggregation von Antikörpern verhindert und für die Anwendung im Auge geeignet ist. Sie setzten NIR-Lichtbestrahlung ein, damit das Bevacizumab die Sklera besser durchdringen kann, und zeigten, dass sich so klinisch relevante Wirkstoffmengen in einer nicht-invasiven einstündigen Behandlung durch die Sklera applizieren lassen [301]. Won et al. hingegen entwickelten mit einer koaxialen 3D-Drucktechnik mehrschichtige Stäbchen für die gleichzeitige Verabreichung von Bevacizumab und Dexamethason. Diese Stäbchen bestanden aus einer PCL-Bevacizumab-Hülle und einem AlginatDexamethason-Kern und wurden mit einem 3D-Biodrucker mit mehreren Druckköpfen hergestellt. Das System ermöglichte eine verzögerte Freisetzung von Bevacizumab über 50 Tage nach einer initialen Burst-Freisetzung über 3 Tage. Dexamethason zeigte eine flutartige Freisetzung innerhalb von $24 \mathrm{~h}$, danach war keine Freisetzung mehr nachweisbar. Die Stäbchen zeigten eine bessere kurz- und langfristige therapeutische Wirksamkeit als gängige intravitreale Injektionen [302].

Weitere Zukunftsperspektiven in der Wundheilung liegen in der Interferenz mit verschiedenen Zytoskelett-Regulatoren (Rho-Kinase-Inhibitoren, Paclitaxel), Wachstumsfaktoren (TGF- $\beta$-, VEGF-Inhibitoren), Zytokinen (Interferon- $\alpha$ ) und Proteinasen (Matrix-Metalloproteinasen) [29, 33, 303]. Welche Formulierungslösungen für die Bekämpfung der Narbenbildung nach einer Glaukomoperation entwickelt werden, bleibt abzuwarten.

\section{Gentherapie}

Dank der Fortschritte in der Genetik und Biotechnologie, die die Manipulation von Vektoren zur Einbringung von extrachromosomalem Material in Zielzellen ermöglicht haben, ist die Gentherapie zu einem neuen strategischen Ansatz geworden, der umfassend untersucht wird. Das Hauptziel dieser innovativen Therapieform besteht darin, mutierte Gene, die für die Entstehung bestimmter Krankheiten verantwortlich sind, zu korrigieren bzw. zu inaktivieren, indem gesundes Genmaterial in das Genom eingebaut wird [304]. Darüber hinaus haben Genome-Editing-Techniken wie CRISPR/Cas9 neue therapeutische Möglichkeiten eröffnet [305].

Angesichts des chronischen Charakters von Glaukom-Erkrankungen können vielversprechende neue Behandlungsstrategien wie die Gentherapie eingesetzt werden, um gezielt bei der zugrunde liegenden Pathophysiologie anzusetzen. Die Gentherapie hat das Potenzial zur lang anhaltenden AID-Senkung durch Steige- rung des konventionellen Abflusses oder des uveoskleralen Abflusses oder Reduktion der Kammerwasserproduktion. Durch Expression von neuroprotektiven Substanzen den Untergang von Nervenzellen zu verhindern oder zu verzögern ein weiterer wichtiger gentherapeutischer Ansatz beim Glaukom [306].

Um Targets für die Gentherapie zu identifizieren, müssen die genetischen Grundlagen des Glaukoms umfassend untersucht und verstanden werden. Forscher haben mindestens 29 Genloci für verschiedene Formen des Glaukoms und von dort aus 12 ursächliche Gene identifiziert [307].

Als geeignete Vektoren für die Glaukom-Gentherapie kommen sowohl virale als auch nicht-virale Vektor-Transportsysteme in Frage. Nicht-virale Vektoren zeichnen sich durch geringe Toxizität und Immunogenität aus. Allerdings sind sie in der Regel weniger effizient beim Einbringen des Genmaterials und erreichen im Vergleich zu virusbasierten Vektoren eine geringere Transfektionseffizienz und ein geringeres Maß an Produktion. Gebräuchliche virale Trägersystemen basieren auf Herpes-Simplex-Viren, Adenoviren, Adeno-assoziierten Viren und Lentiviren. Hiervon haben sich rekombinante Adeno-assoziierte virale Vektoren (AAV) bisher als die vielversprechendsten erwiesen [308]. Zu den nicht-viralen Systemen zur Einschleusung von Genmaterial zählen Liposomen/synthetische Polymere, direkte Injektion von nackter DNA ins Gewebe, RNA-Interferenz und Elektroporation [306].

Durch Reduktion der zellulären Kontraktilität mittels Hemmung der Rho-Kinase (Rho-GTPase) konnte die Abflusskapazität in Schweine- und Menschenaugen in der Organkultur sowie in Affenaugen in vivo erhöht werden. Verschiedene Gene (DN Rho, C3, DNRK, Caldesmon) wurden untersucht, um diesen Rho-KinaseSignalweg, der für die Modulation des Kammerwasserabflusses eine zentrale Rolle spielt, durch Expression von Protein-Inhibitoren dieses Signalwegs zu manipulieren [309-311]. Vittitow et al. zeigten in ihren Untersuchungen, dass die Inaktivierung von RhoA durch adenoviralen Gentransfer in die intakte Abflussbahn beim Menschen die Abflusskapazität erhöht. Sie postulierten, dass adenovirale Vektoren mit der dominant-negativen Form von RhoA als Gentherapie zur Modulation der Abflusskapazität eingesetzt werden könnten [312].

Die Gentherapie könnte auch zur Steigerung des uveoskleralen Abflusses genutzt werden, indem die endogenen Targets verstärkt bzw. unterdrückt werden, die letztlich für die durch MMP und Gewebe-Inhibitoren der MMP (TIMP) verursachte Abflussförderung verantwortlich sind.

Einen neuartigen Ansatz zur Behandlung des Steroid-induzierten Glaukoms stellten Spiga et al. vor. Sie konstruierten einen neuartigen Glukokortikoid-induzierbaren Adenovirusvektor, der zur Überproduktion von MMP1 nur in Gegenwart von Dexamethason führt [313]. Die Ergebnisse von Kee et al. deuten außerdem darauf hin, dass möglich ist, zur Behandlung des Glaukoms bei der Expression des Stromelysin-Gens innerhalb der uveoskleralen Abflussbahn anzusetzen [314].

Da im Gen für Myocilin (MYOC) Mutationen gefunden wurden, die mit dem primären Offenwinkelglaukom assoziiert sind, ist 
auch die Inhibition des Myocilin-Gens durch RNA-Interferenz mit synthetischer small interfering RNA (siRNA) und short hairpin RNA (shRNA) untersucht worden.

Comes et al. brachten nackte siRNA durch intrakamerale Perfusion in das intakte menschliche Trabekelwerk ein, um das MYOCGen zu inhibieren, und ihre Ergebnisse belegen die erfolgreiche Reduktion der MYOC-Ausschüttung durch siRNA-behandelte Zell- und Organkulturen [315]. Ein weiterer interessanter Ansatz wurde kürzlich von Jain et al. vorgestellt, die Genome Editing mit CRISPR-Cas9 bei kultivierten humanen Trabekelzellen und in einem MYOC-Mausmodell des primären Offenwinkelglaukoms anwendeten, um einen Knockdown des mutierten MYOC-Gens zu erzielen, und so den AID zu senken und weitere glaukomatöse Schädigung zu verhindern [316].

Mit siRNA, die gegen das Carboanhydrase-Gen IV und den $\beta 2$ adrenergen Rezeptor gerichtet sind, konnte in einem Kaninchenmodell okulärer Hypertension eine Senkung des AID durch Hemmung der Kammerwassersekretion herbeigeführt werden [318].

Der Einsatz von gegen den $\beta 2$-adrenergen Rezeptor $(A D R \beta 2)$ gerichteter siRNA könnte ebenfalls eine interessante Strategie für die Glaukomtherapie darstellen. SYL040012, eine gegen ADR $\beta 2$ gerichtete siRNA, befindet sich derzeit in der Entwicklung für die Anwendung beim Glaukom. Nach topischer okulärer Instillation im Tiermodell hemmt SYL040012 spezifisch die Synthese des ADR $\beta 2$, was zur Senkung des AID führt [319]. In einer klinischen Phase-I-Studie an gesunden Probanden mit normalen AID-Werten $(<21 \mathrm{mmHg})$ zeigten SYL040012-Augentropfen auch in der höchsten verwendeten Dosierung gute Sicherheit und Verträglichkeit [320]. SYL040012 befindet sich nun in Phase 2 der klinischen Prüfung [321].

Pfeiffer et al. untersuchten kürzlich die intravitreale Injektion von ISTH0036. Das vollständig Phosphorothioat-modifizierte 14merAntisense-Oligonukleotid ist selektiv gegen den transformierenden Wachstumsfaktor beta 2 (TGF- $\beta 2$ ) gerichtet, welcher mit den wichtigsten pathophysiologischen Ereignissen beim Glaukom in Verbindung gebracht worden ist. Die Studie bei Patienten mit primärem Offenwinkelglaukom ergab, dass eine einmalige Gabe von ISTH0036 am Ende der Trabekulektomie sicher war und zu AIDWerten führte, die über den dreimonatigen postoperativen Beobachtungszeitraum hinweg durchgängig unter $10 \mathrm{mmHg}$ lagen [322].

Im Gegensatz zu den meisten Glaukomformen mit frühem Krankheitsbeginn, die in der Regel eine einzige genetische Ursache haben, ist das im Erwachsenenalter auftretende Glaukom von unklarer, heterogener Ätiologie, an der multiple genetische Faktoren, individuelle Risikofaktoren und Umweltfaktoren beteiligt sind, was eine Standardisierung des gentherapeutischen Vorgehens erschwert. Gentherapien für Glaukomerkrankungen im Erwachsenenalter zielen deshalb bisher vor allem auf Neuroprotektion ab, um den Untergang der retinalen Ganglienzellen (RGC) zu verlangsamen oder zu verhindern [308]. Studien zur intraokulären Einbringung von Genen für neurotrophe Faktoren (wie z.B. den Brain-Derived Neurotrophic Factor (BDNF), Ciliary Derived
Neurotrophic Factor (CNTF) oder Neurotrophin 4 (NT-4)) haben weitere ermutigende Ergebnisse geliefert [323-327].

Petrova et al. veröffentlichten 2020 eine sehr wichtige Studie, in der sie eine robuste Axon-Regeneration im adulten ZNS durch Überexpression des Adapterproteins Protrudin nachwiesen. Die Expression der mRNA von Protrudin (Zfyve27), das normalerweise in nicht-regenerativen Neuronen nur in geringen Mengen vorkommt, förderte die Regeneration im adulten ZNS durch Bereitstellung eines Gerüsts zur Verbindung von axonalen Organellen, Motoren und Membranen. Dies könnte für die Gentherapie des Glaukoms sehr wichtig sein, da die Protrudin-Expression auch die RGC-Regeneration fördern kann. In dieser Studie wurden ein Sehnervkompressions-Modell sowie ein akutes retinales Explantat-Modell und ein AAV-Vektor verwendet, um die Auswirkungen der Protrudin-Expression auf die Neuroprotektion von RGC zu untersuchen. Die Ergebnisse deuten darauf hin, dass sowohl das phosphomimetische als auch das Wildtyp-Protrudin bewirkten, dass nur zwei Wochen nach der Sehnervkompression eine große Anzahl von Axonen sich über lange Strecken regenerierten, wobei nur das phosphomimetische Protrudin einen ausgeprägten Effekt auf das neuronale Überleben 2 Wochen nach der Kompression hatte. Die Ergebnisse weisen außerdem darauf hin, dass beide Formen von Protrudin in einem retinalen Explantatmodell für RGC-Schädigung und zwei Wochen nach Sehnervenquetschung vollständig neuroprotektiv wirkten [328].

Unserer Einschätzung nach wird diese Forschungsrichtung andere, herkömmliche Ansätze der Glaukomtherapie weitgehend ersetzen. Doch gibt es noch erhebliche Herausforderungen zu bewältigen, bevor die Gentherapie zur Behandlung des Glaukoms eingesetzt werden kann. Ein besseres Verständnis der molekularen Pathogenese und der genetischen Grundlagen der Erkrankung, die Optimierung der Vektorsysteme für eine höhere Transfektionseffizienz und eine lang anhaltende Genexpression auf therapeutischem Niveau in den ausgewählten Zielzellen sowie die Entwicklung besser geeigneter Tiermodelle werden dazu beitragen, das klinische Potenzial dieser vielversprechenden neuen therapeutischen Strategie zu heben.

\section{Neuroprotektion}

Die Neuroprotektion ist unabhängig von der Augeninnendrucksenkung eine Behandlungsstrategie, die darauf abzielt, den Untergang retinaler Ganglienzellen zu verhindern und so die Erblindung zu vermeiden oder hinauszuzögern [329]. Das Absterben der retinalen Ganglienzellen führt zunächst zu Gesichtsfeldausfällen. Neuroprotektive Arzneimittel wirken in Fällen, in denen der neuronale Untergang langsam voranschreitet, besser als bei schnellem Absterben der Neuronen. Da eines der Hauptmerkmale des Glaukoms das langsame Absterben von Neuronen ist, könnte Neuroprotektion hier einen langsameren und geringeren Verlust von Ganglienzellen bewirken. Der Nutzen von neuroprotektiver Medikation im Rahmen der Glaukombehandlung ist größer und das Ausmaß an Nebenwirkungen geringer, wenn die entsprechende Wirkstoffmenge auf die Netzhaut gegeben wird [330]. Strategien zur Neuroprotektion basieren auf zwei Ansätzen: Nut-
64

Kompass Ophthalmol 2021;7:47-69 DOI: $10.1159 / 000516684$ 
zung von Signaltransduktionswegen zur Stimulierung des Zellüberlebens oder zur Inhibition des Zelltodes, damit die Zellen widerstandsfähiger gegen ansonsten pathologischen Insult werden [331]. Die Neuroprotektion beim Glaukom ist mit vielfältigen Herausforderungen verbunden, unter anderem hinsichtlich der Entwicklung adäquater Tiermodelle, die der menschlichen Erkrankung entsprechen. Für Neurodegeneration sind zwar Tiermodelle entwickelt wurden, doch nur wenige Ansätze konnten bisher in die klinische Prüfung überführt werden [332].

\section{Glutamat-Antagonisten}

Eine exzitotoxische Wirkung von Glutamat auf die Netzhaut ist auf hohe extrazelluläre Glutamatkonzentrationen zurückzuführen. Das Glutamat interagiert mit den exzitatorischen Glutamatrezeptoren der RGC und bewirkt deren Überexpression. Die Akkumulation von Glutamat bewirkt eine Überstimulation der N-Methyld-Aspartat- (NMDA-)Rezeptoren. Die dadurch einströmenden Kalzium-Ionen führen zur Entstehung von freien Radikalen und letztlich zur Apoptose. Durch die Modulation der NMDA-Rezeptoren lässt sich die Glutamataktivität vermindern [333]. Dreyer et al. wiesen eine Verdoppelung des Glutamatspiegels im Glaskörper von Glaukompatienten nach, was auf die Möglichkeit eines exzitotoxischen Mechanismus als Grundlage des RGC-Untergangs hinweist [334].

MK801, auch bekannt als Dizocilpinmaleat, ist ein nicht-kompetitiver NMDA-Antagonist und gilt als der stärkste Glutamatinhibitor und neuroprotektive Wirkstoff in der experimentellen Behandlung des Glaukoms. Aufgrund seiner langen Halbwertszeit, der Hemmung der physiologischen Funktionen von Glutamat und der damit verbundenen Neurotoxizität wurde es bisher nicht in höherrangigen klinischen Studien untersucht [335].

Memantin ist ein nicht-kompetitiver NMDA-Rezeptorantagonist, der in der Behandlung von mittelschwerem bis schwerem Morbus Alzheimer eingesetzt wird und in einem Glaukom-Affenmodell vielversprechende Ergebnisse gezeigt hat [336]. NMDA-Rezeptoren kommen im gesamten zentralen Nervensystem verbreitet vor und spielen wichtige Rollen für die Neurotransmission und die normale Funktion der Nervenzellen. Eine Überstimulation in Gegenwart von zu viel Glutamat kann jedoch zu Ca2+-vermittelter Neurotoxizität führen. Eine Dysregulation dieser Kaskade ist umfassend mit chronischen neurodegenerativen Erkrankungen einschließlich des Glaukoms in Verbindung gebracht worden [331]. Bis(7)-tacrin ist ein neuerer NMDA-Rezeptorantagonist mit außergewöhnlicher neuroprotektiver Aktivität. Der Wirkstoff hemmt die Acetylcholinesterase und die Stickstoffmonoxidsynthase und blockiert so den NMDA-Rezeptor [337]. Bis(7)-tacrin zeigte in einer Studie an RGC in Kultur eine stärkere neuroprotektive Wirkung als Memantin [338]. Amantadin, psychotropes Tetrahydrocannabinol und nicht-psychotropes Cannabinol erzielen neuroprotektive Wirkung durch Reduktion der NDMA-Aktivität [339, 340].

\section{Neurotrophe Faktoren}

Der Mangel an neurotrophen Faktoren im Sehnerv trägt zum Auftreten und Fortschreiten der glaukomatösen Optikusneuro- pathie (GON) bei, die durch erhöhten AID verursacht wird. Eine Verbesserung der neurotrophen Unterstützung könnte den RGCUntergang im Rahmen des Glaukoms verlangsamen [341]. Gliazellen und Neuronen tragen Rezeptoren für verschiedene neurotrophe Faktoren. Die Abwesenheit solcher neurotrophen Faktoren führt zur Blockade des axonalen Transports und schließlich zur Apoptose [342].

Der Brain-Derived Neurotrophic Factor (BDNF) ist ein Vertreter einer Gruppe von Wachstumsfaktorproteinen. Er ist von großer Bedeutung für die Funktion und das Überleben der RGC.

Intravitreale Injektionen mit BDNF haben vor allem den Nachteil, dass das Protein nicht kontinuierlich bereitgestellt werden kann und immer wieder injiziert werden muss. Um dieses Problem zu beheben, wurden neuartige andere Ansätze auf der Basis von Gentherapie oder Stammzellen entwickelt [341].

Auch der ziliare neurotrophe Faktor (CNTF) hat einen neurotrophen Effekt auf RGC gezeigt. Die intravitreale Gabe von CNTF kann RGC vor der Apoptose schützen. Pease et al. untersuchten, ob die Überexpression von CNTF in der Netzhaut von WistarRatten mit chronischer okulärer Hypertension eine RGC-protektive Wirkung hat. In den Augen, die mit intravitrealen Injektionen von CNTF-AAV-Vektoren behandelt wurden, traten genau $15 \%$ weniger RGC-Axonverlust ein [344].

Artemin, Basic Fibroblast Growth Factor, Interleukin-6 und Erythropoietin sind weitere trophische Faktoren oder Zytokine, für die eine neuroprotektive Wirkung postuliert worden ist [333]. Die effektive und anhaltende Versorgung der Netzhaut mit trophischen Faktoren ist eine Herausforderung, da die Molekülgröße dieser Proteine ihre Passage durch die Blut-Retina-Schranke erschwert. Ein alternativer Weg zur Applikation trophischer Faktoren in die Netzhaut könnte die intravitreale Injektion sein, doch dieser Verabreichungsweg ist bei chronischen Erkrankungen wie dem Glaukom nicht praktikabel. Die Einarbeitung der neurotrophen Faktoren in Wirkstoffabgabesysteme zur intraokularen Implantation ist ein möglicher Ansatz für die langfristige Bereitstellung solcher Wirkstoffe. Die Einbringung trophischer Faktoren mittels viraler Vektoren hat zwar in Tiermodellen der Netzhautdegeneration protektive Effekte gezeigt, doch verschiedene Probleme z.B. bei der präzisen Dosierungskontrolle, lassen die klinische Anwendbarkeit dieses Ansatzes fraglich erscheinen [346].

\section{Antioxidanzien}

Gewebe- und Kammerwasserproben von glaukomatösen Augen zeigen verminderte Antioxidanzienkonzentrationen, erhöhte Marker für oxidativen Stress, Antikörper gegen die Glutathion-STransferase, verminderte Glutathion-Plasmaspiegel, erhöhte Plasmaspiegel von Lipidperoxidationsprodukten, erhöhte Konzentrationen reaktiver Sauerstoffspezies (ROS) [347], verminderte Zellmembranpotenziale und verminderte Adenosintriphosphat- (ATP-)Produktion im Trabekelwerk. Auf diese Weise führt oxidativer Stress zum Absterben von RGC mit Schädigung des Sehnervenkopfs und Trabekelwerks. Antioxidanzien können ROS neutralisieren und ihre Akkumulation im Trabekelwerk verhindern [348, 349]. Die zellulären Abwehrmechanismen gegen 
oxidativen Stress umfassen Superoxiddismutase-, Glutathion(GSH-) und Thioredoxin- (TRX-)Systeme [350].

Vitamin-E-Mangel kann die Konzentration von Lipidperoxidationsprodukten erhöhen und dadurch zum Tod von RGC führen. Die subkutane Applikation von Vitamin E kann Retinaschädigung durch hohen AID verhindern [351].

Auch Nicotinamid (Vitamin B3) kann als neuroprotektiver Wirkstoff eingesetzt werden. Nicotinamid-Adenin-Dinukleotid (NAD) ist ein essenzieller Cofaktor in den Redoxreaktionen der mitochondrialen Atmungskette, die zur Aufrechterhaltung einer ausreichenden ATP-Konzentration erforderlich sind. Der intraokulare Anteil des RGC-Axons ist nicht myelinisiert und hat daher einen besonders hohen Energiebedarf. Nicotinamid-Mangel und NAD-Depletion haben daher das Potenzial, den Mitochondrienund Energiestoffwechsel sowie die Funktion der Ganglienzellen schwer zu stören [331].

Coenzym Q10 (CoQ10) stabilisiert das mitochondriale Membranpotential, unterstützt die ATP-Synthese und hemmt die Entstehung von ROS. Es verhindert außerdem Netzhautschäden, die durch transiente ischämische Traumata infolge eines akut erhöhten AID verursacht werden. CoQ10 inhibiert in vivo die mitochondriale Depolarisation, indem es die Bildung der zum mitochondrialen Permeabilitätsübergang führenden Pore verhindert und so die RGC vor Glutamat-Exzitotoxizität schützt. Es reduziert möglicherweise die Akkumulation von extrazellulärem Glutamat, mindert dadurch die schädigende Auswirkung der Ischämie/Reperfusion auf den mitochondrialen Energiestoffwechsel und die Glutamattransporterfunktion und verhindert dadurch die Apoptose der RGC [352].

Alpha-Liponsäure und Superoxid-Dismutase (SOD) sind die beiden anderen wichtigsten Antioxidanzien. Nebbioso et al. gelangten zu dem Schluss, dass eine 8-wöchige Behandlung mit AlphaLiponsäure und SOD die RGC vor Schäden schützt, die durch akute okuläre Hypertension induziert werden [354].

Melatonin kann dank seiner antioxidativen, antiexzitotoxischen und antiinflammatorischen Wirkung zur Neuroprotektion eingesetzt werden. Es vermag die Blut-Hirn-Schranke zu passieren und hat zudem eine kurze Halbwertszeit und keine signifikanten Nebenwirkungen [355].

Citicolin (Cytidin 5'-diphosphocholin) zeigt eine potenzielle schützende Wirkung auf RGC aufgrund seiner antiapoptotischen Effekte im mitochondrienabhängigen Zelltod-Mechanismus. Außerdem spielt es eine auxiliäre Rolle bei der Axonregeneration [357]. Parisi et al. fanden heraus, dass die neuroprotektive Wirkung von Citicolin (als Augentropfen) unabhängig von der AIDsenkenden Wirkung ist, und sie bestätigten, dass die Anwendung von Citicolin-Augentropfen das Pattern-Elektroretinogramm (PERG) und die visuell evozierten Potenziale (VEP) signifikant verbesserte [358].

Bei Glaukompatienten mit Normaldruckglaukom inhibierte Palmitoylethanolamid verschiedene für das Glaukom relevante inflammatorische Signalkaskaden, und es vermochte den AID zu senken und die Gesichtsfeldindizes zu verbessern, was auf eine duale AID-senkende und neuroprotektive Wirkung hinweist [359].
Andere Antioxidanzien wie Vitamin C, $\alpha$-Tocopherol oder Ginkgo biloba können ebenfalls eingesetzt werden, um RGC-Schädigung zu verhindern. Polyphenolische Flavonoide aus Ginkgo sind in der Lage, in die Mitochondrien einzudringen, und können daher über die Aufrechterhaltung des mitochondrialen Stoffwechsels neuroprotektiven Nutzen zeigen. Andererseits kann GinkgoExtrakt das Blutungsrisiko bei Operationen erhöhen, so dass die Anwendung nur mit besonderer Vorsicht erfolgen sollte [329].

\section{Kalziumantagonisten}

Die neurotoxische Wirkung von NMDA wird durch den Einstrom von Kalzium in die Nervenzellen vermittelt, der zum apoptotischen Zelltod führt. Kalziumkanalblocker (CCB) können den durch Kalziumeinstrom verursachten RGC-Tod verhindern. Zusätzlich verbessern sie die lokale Durchblutung in ischämischen Geweben, indem sie die Vasodilatation induzieren. Verschiedene Kalziumkanalblocker wie Iganidipin, Nimodipin und Lomerizin bewirkten in Studien eine signifikante Verbesserung der Lebensfähigkeit gereinigter Ratten-RGC unter Hypoxie [360]. Koseki et al. berichteten, dass in einer placebokontrollierten Studie bei Patienten mit primärem Offenwinkelglaukom (POWG) die orale Gabe von Nilvadipin über 3 Jahre die Verschlechterung des Gesichtsfelds leicht verlangsamte und den Erhalt des Sehnervenkopfsaums begünstigte [361]. In einer anderen Laborstudie konnte mit Diltiazem im Gegensatz zu Nilvadipin die Glutamat-induzierte RGC-Apoptose nicht verhindert werden [362]. Bei Patienten, die CCB anwenden, kann es zu einer verminderten Durchblutung kommen, was die Autoregulation der Blutzirkulation stören und pathologische Veränderungen der RGC beschleunigen kann.

\section{Alpha-2-adrenerge Agonisten}

Brimonidin ist ein sehr gebräuchliches okuläres Hypotensivum, das durch die Aktivierung des a2-adrenergen Rezeptors und Verringerung der Kammerwasserproduktion wirkt. Seine neuroprotektiven Effekte sind unabhängig von seiner Wirkung auf den AID. Diese Effekte werden über eine Vielzahl von Mechanismen vermittelt, einschließlich der Hochregulierung des Brain-Derived Neurotrophic Factor (BDNF) und des Basic Fibroblast Growth Factor (bFGF), des Stickstoffmonoxid-Synthase-3-Stoffwechsels und der retinalen Vasomodulation, der Aktivierung von Zellüberlebens-Signalwegen und Apoptoseprävention sowie der Modulation der NMDA-Rezeptorfunktion [331]. Wenn Brimonidin intravitreal statt topisch verabreicht wird, kann das Überleben der RGC signifikant verbessert werden, was auf die Hochregulierung der endogenen Expression von BDNF in den RGC zurückzuführen ist [365]. Basierend auf einer systematischen Übersicht und Metaanalyse der Evidenz zu den neuroprotektiven Eigenschaften von Brimonidin beim Glaukom gelangen Scuteri et al. zu dem Schluss, dass weitere Untersuchungen zur Beurteilung der Wirksamkeit von Brimonidin in Bezug auf die Gesichtsfeldverschlechterung beim Glaukom durchgeführt werden sollten und dass die Erkenntnislage zu den neuroprotektiven Effekten nicht schlüssig ist und ein stärkeres Fundament braucht, z.B. in Form groß angelegter, doppelt verblindeter, randomisierter klinischer Studien [366].
66

Kompass Ophthalmol 2021;7:47-69

DOI: $10.1159 / 000516684$ 


\section{Stickstoffmonoxid-Synthase-Inhibitoren}

Eine Form der Stickstoffmonoxid-Synthase (NOS), NOS-2, zeigt neurotoxische Effekte [367]. Für Aminoguanidin und N-nitro-larginin wurden inhibitorischen Effekte auf NOS-2 in Bezug auf Neuroprotektion und verzögerte RGC-Degeneration bestätigt [368]. In einer von Neufeld durchgeführten Studie bewirkte die orale oder topische Gabe von Aminoguanidin in Rattenmodellen mit entweder chronischer oder akuter AID-Erhöhung signifikante Verbesserungen des RGC-Überlebens. Ein anderer NOS-2-Inhibitor, SC-51, zeigte ähnliche protektive Effekte auf RGC in einem Wanderratten-Modell von chronisch erhöhtem AID [369]. Andere Studien zeigten jedoch keine signifikanten Veränderungen der NOS-2-Expression und keinen Effekt der Aminoguanidin-Behandlung auf die glaukomatöse Schädigung bei Ratten [370].

\section{Glaukom-Medikamente mit durchblutungsregulierender Wirkung}

Eine verbesserte Regulation der Durchblutung des Auges kann in der Folge eine bessere Neuroprotektion ermöglichen. Wirkstoffe, die für dieses Anwendungsgebiet untersucht wurden, sind CAI, Latanoprost und Betaxolol [371]. Durch topische Applikation von Betaxolol wurde bei SD-Ratten mit akuter okulärer Hypertension die Integrität der inneren plexiformen und nukleären Retinaschicht aufrechterhalten. Collignon-Brach berichtete, dass Patienten mit okulärer Hypertension oder chronischem Offenwinkelglaukom nach dreijähriger Einnahme von Betaxolol Vorteile hinsichtlich des Gesichtsfelds hatten, obwohl Timolol den AID wirksamer senkte [372].

\section{Hitzeschockproteine}

Hitzeschockproteine (HSP), auch bekannt als Stressproteine oder molekulare Chaperones, liegen in zahlreichen Zellen vor. Sie werden für die normale Funktion der Zellproteine benötigt und hemmen den Ablauf apoptotischer Prozesse. Sie können den Zelltod sowohl direkt verhindern (durch Hemmung proapoptotischer Faktoren) als auch auf indirekten Wegen (durch Schutz vor oxidativem Stress und Suppression proinflammatorischer Zytokine) [373]. Wenn das Auge Hitze oder Strahlung ausgesetzt ist, wird eine okuläre Stressreaktion ausgelöst, und der HSP-Spiegel steigt an. Hitzeschockfaktoren (HSF) sind im Zellkern lokalisiert und bilden durch Bindung an Hitzeschockelemente (HSE) eine komplexe Struktur im Promoterbereich des jeweiligen Gens. Dies führt zur Transkription von HSP, und die Stressreaktion wird primär durch HSF auf der transkriptionellen Ebene reguliert [374].

\section{Stammzelltransplantation}

Stammzellen können neue Körperzellen aller Art hervorbringen und die Regeneration geschädigter Zellen induzieren. Die Bereitstellung verschiedener neurotropher Faktoren ist weithin als der Mechanismus akzeptiert, über den transplantierte Zellen die Exzitotoxizität modulieren können. Einer der Vorteile von Stammzelltransplantationen zur RGC-Neuroprotektion ist die lang anhaltende und lokal begrenzte Wirkung, von der man sich auch eine bessere Compliance der Patienten verspricht. Langzeit-Sicherheitsstudien sind unbedingt erforderlich, um sicherzustellen, dass der potenzielle Nutzen der Neuroprotektion das Risiko der Tumorauslösung überwiegt [375]. 
Im Gegensatz zum peripheren Nervensystem (PNS) besitzt das zentrale Nervensystem (ZNS) nicht die Fähigkeit zur Selbstregeneration. Die Entwicklung von Stammzellen zu gesunden RGC erfordert ihre Integration in die Netzhaut, wo sie zur Ausbildung neuer Axone angeregt werden, die aus dem Auge heraus- und in den Sehnerv hineinwachsen, sowie die Bildung neuer und geeigneter Synapsen, wenn sie ihr synaptisches Ziel im Zwischenhirn erreichen. All dies ist hochgradig schwierig zu erreichen [376].

Die Regeneration von RGC kann von verschiedenen Zellarten ausgehen, z.B. von embryonalen Stammzellen (ESC), induzierten pluripotenten Stammzellen (iPSC), mesenchymalen Stammzellen (MSC), humanen embryonalen Stammzellen (hESCs) oder retinalen Progenitorzellen (RPC) [377].

Dreidimensionale (3D) retinale Organoide sind in-vitro-Gewebestrukturen, die aus selbstorganisierenden Kulturen von differenzierenden hESC oder iPSC gewonnen werden [378]. Sie rekapitulieren viele Aspekte der Netzhautentwicklung in vitro, exprimieren die gleiche Sequenz von Transkriptionsfaktoren, die die endogene retinale Entwicklung charakterisieren, und organisieren sich in Schichten, die der nativen Netzhaut ähnlich sind. Große Mengen immunkompatibler, gesunder RGC können aus iPSCOrganoiden aufgereinigt und Patienten transplantiert werden, da iPSC-basierte retinale Organoide einen funktionalen, wenngleich einfachen, retinalen Schaltkreis entwickeln [379]. In Kombination mit Genome-Editing-Tools könnten 3D-Retina-Organoide zu einer zuverlässigen und erneuerbaren Quelle transplantierbarer Zellen zur personalisierten Behandlung von Krankheiten werden, welche durch Fehlfunktion oder Degeneration von Photorezeptoren oder RGC verursacht werden [378].

Stammzelltransplantationen sind als therapeutische Option umfassend erforscht worden, um die mangelnde Fähigkeit der menschlichen Retina auszugleichen, geschädigte Photorezeptoren (PR) oder retinales Pigmentepithel (RPE) zu regenerieren. Die Gewinnung von Photorezeptoren aus retinalen Organoiden hat großes Potenzial für die therapeutische Photorezeptortransplantation. Aus Stammzellen gewonnene Photorezeptoren können weiterentwickelt werden, z.B. durch die Expression von optogenetischen Instrumenten zur Untersuchung der funktionalen Integration in die Empfänger-Netzhaut [380]. Während neu integrierte Photorezeptoren nur kurze Verbindungen zu den darunter liegenden Horizontal- und Bipolarzellen brauchen, müssen RGC lange Axone ausbilden und funktionelle Verbindungen zu spezifischen Zielen im Gehirn herstellen [381].

Mit der Transplantation von RGC konnte ein gewisser Grad an funktioneller Erholung der Retina nach NMDA-induzierter RGC-Schädigung erreicht werden. Die beobachtete funktionelle Rettung lässt sich durch neuroprotektive Effekte erklären. Die einzigen RGC-Transplantationen, die bisher zur erfolgreichen Integration elektrophysiologisch funktionsfähiger Neuronen führten, sind für primäre RGC beschrieben worden, wobei die Gesamterfolgsrate lediglich $10 \%$ betrug $[382,383]$.

Angesichts dieser Herausforderungen steht die RGC-Transplantation im Vergleich zur RPE- oder PR-Transplantationen noch am Anfang der präklinischen Prüfung. Die Entwicklung auf Emp- fängerseite ist entscheidend für den erfolgreichen Zellersatz bei Glaukompatienten, doch die Ursache hierfür ist noch ungeklärt. Ein Vergleich von auf Stammzellen zurückgehenden RGC und primären RGC im frühen postnatalen Stadium wäre aufschlussreich, um zellstadienspezifische Parameter zu identifizieren, die die Integration in die reife Retina fördern. Trotz erfolgreicher Transplantatakzeptanz in einigen Fällen haben Studien bisher keine offensichtliche funktionelle Verbesserung nach RGCTransplantation gezeigt, was auf unzureichende Zellintegration und Axonwachstum zurückzuführen ist [384].

Aufgrund der komplexen Morphologie der neuralen Retina und der unterschiedlichen Zelltypen mit ihren multiplen synaptischen Verbindungen reicht die Transplantation eines einzelnen Zelltyps normalerweise nicht aus, um die fortschreitende Netzhautdegeneration zu reparieren. Eine Lösung für dieses Problem könnte die Herstellung von neuralem Netzhautgewebe aus pluripotenten Zellen in vitro. MSC aus Fettgewebe und Knochenmark wurden aufgrund ihrer neuroprotektiven Wirkung als potenzielle Zellquelle für die Transplantation in Tiermodellen der RGCDegeneration untersucht. Nach der Transplantation der MSC war eine Zunahme der Anzahl der RGC und RGC-Axone, der Erhalt von ONL-Zellen, ein verlängertes Überleben von PR, vermehrte Sekretion von NTF sowie Immunmodulation und Neurovaskularisierung zu beobachten [387]. Die Wirkmechanismen der MSC umfassen möglicherweise die Hochregulierung von trophischen Faktoren wie FGF-2 und die Modulation der Neuroinflammation durch vermehrte Expression von Zytokinen wie IL-1 $\beta$ im geschädigten Gewebe [388]. Aus Organoiden stammende RGC könnten helfen zu klären, welche Faktoren die axonale Aussprossung fördern [389]. Eastlake et al. wiesen nach, dass Müller-Gliazellen, die aus retinalen Organoiden aus hiPSC isoliert wurden, die Sehfunktion von NMDA-depletierten RGC bei Ratten teilweise wiederherzustellen vermögen [390].

Der potenzielle therapeutische Wert von RGC aus retinalen Organoiden muss noch gründlich untersucht werden. Herausforderungen stellen sich sowohl bei der Definition des anpassbaren Einbringungsweges für einen effektiven retinalen Organoidtransfer in die Empfänger-Retina als auch bei der Frage, wie die Injektion körperfremder Zellen die native Netzhautumgebung beeinflusst und ob Spender-RGC sich integrieren und funktionelle Schaltkreise bilden, die die visuelle Verarbeitung wiederherstellen. Um die Sehfunktion wiederherzustellen, müssen die transplantierten RGC Axone wachsen lassen, die über den Sehnervenkopf hinausreichen; weitere Erfordernisse sind die Remyelinisierung durch Oligodendrozyten und die korrekte Führung zu Anschlussstellen im Gehirn, wo neue synaptische Verbindungen gebildet werden können kann [391]. Wenn es gelingt, diese Hürden zu überwinden, könnten aus Stammzellen gewonnene RGC oder RGC-Vorläufer zu einer praktischen und bevorzugten Strategie für die Behandlung von Patienten mit Glaukom werden.

Ungeachtet der positiven Studienergebnisse in der Glaukomtherapie haben neuroprotektive Arzneimittel den großen Nachteil, dass es für sie keinen adäquaten Verabreichungsweg gibt. Bei The-
68

Kompass Ophthalmol 2021;7:47-69 DOI: $10.1159 / 000516684$ 
rapien zur topischen Anwendung zeigen die Patienten mangelnde Therapietreue. Arranz-Romera et al. entwickelten mehrfach beladene PLGA-Mikrosphären, in die sie eine Kombination aus drei neuroprotektiven Wirkstoffen einarbeiteten (Melatonin, Coenzym Q10 und Dexamethason). Ihr Ziel war die Entwicklung eines neuartigen intraokulären Systems für die verzögerte Wirkstoffabgabe in der Behandlung des Glaukoms. Nach Anpassung der Partikelgröße und -form zur effektiven Inkorporation in die intravitreale Injektion erreichten sie so die gemeinsame Verabreichung der enthaltenen Wirkstoffe, gestreckt über 30 Tage mit geringer initialer Burst-Freisetzung. Hierbei war eine signifikante Verbesserung der neuroprotektiven Effekte im Vergleich zu Mikrosphären ohne oder mit nur einem Wirkstoff zu verzeichnen, was darauf hindeutet, dass die mehrfach beladenen PLGA-Mikrosphären einen vielversprechenden Lösungsansatz für die Behandlung des Glaukoms und anderer neurodegenerativer Erkrankungen darstellen [392].

Die meisten neuroprotektiven Wirkstoffe haben ihre Wirksamkeit in Tiermodellen gezeigt, und diese Ergebnisse sind nicht immer auf den Menschen übertragbar. Ihr Potenzial, die Schädigung der RCG zu verhindern, ist unbestritten, doch es sind weitere klinische Studien erforderlich, um das genaue Vorgehen für eine effektive Therapie zu etablieren.

\section{Beiträge der einzelnen Autoren}

Konzepterstellung: O.R.; Verfassen - Ursprungsentwurf: O.R., A.T. und N.O.; Verfassen - Redaktionelle Überarbeitung: O.R., A.T., N.O., M.S. und L.H.; Leitung: J.H. und E.V.; Erstellung der Abbildungen: A.T. Alle Autoren haben die veröffentlichte Version des Manuskripts gelesen und freigegeben

\section{Finanzierung}

Diese wissenschaftliche Arbeit wurde nicht durch Drittmittel unterstützt.

\section{Interessenkonflikte}

Alle Autoren erklären, dass keine Interessenkonflikte bestehen.

\section{Lizenzangabe}

Rahić O, Tucak A, Omerović N, Sirbubalo M, Hindija L, Hadžiabdić J, Vranić E: Novel Drug Delivery Systems Fighting Glaucoma: Formulation Obstacles and Solutions. Pharmaceutics. 2020;13(1):28 (DOI: 10.3390/ pharmaceutics13010028. ${ }^{\circledR} 2020$ The Authors. Licensee MDPI, Basel, Switzerland (gekürzte Übersetzung; Kapitel Introduction und Conclusions komplett sowie Teile der Kapitel Novel Drug Delivery Systems und Future Perspectives gekürzt; Institutional Review Board Statement, Informed Consent Statement und Data Availability Statement gekürzt), lizensiert unter CC BY 4.0 (https://creativecommons.org/licenses/by/4.0/deed.de).

\section{Literatur}

Die Literatur ist unter www.karger.com/doi/10.1159/000516684 abrufbar. 